\title{
Imaging Cognitive Impairment and Impulse Control Disorders in Parkinson's Disease
}

\author{
Antonio Martín-Bastida ${ }^{1,2}$, Manuel Delgado-Alvarado ${ }^{3}$, Irene Navalpotro-Gómez ${ }^{4,5,6}$ and \\ María Cruz Rodríguez-Oroz ${ }^{1,2,7 *}$

\begin{abstract}
${ }^{1}$ Department of Neurology, Clinica Universidad de Navarra, Pamplona, Spain, ${ }^{2}$ CIMA, Center of Applied Medical Research, Universidad de Navarra, Neurosciences Program, Pamplona, Spain, ${ }^{3}$ Neurology Service, Sierrallana Hospital-IDIVAL, University of Cantabria, Satander, Spain, ${ }^{4}$ Cognitive Impairment and Movement Disorders Unit, Neurology Department, Hospital del Mar, Barcelona, Spain, ${ }^{5}$ Clinical and Biological Research in Neurodegenerative Diseases, Integrative Pharmacology and Systems Neurosciences Research Group, Neurosciences Research Program, Hospital del Mar Research Institute (IMIM), Barcelona, Spain, ${ }^{6}$ Barcelonabeta Brain Research Center, Pasqual Maragall Foundation, Barcelona, Spain,
\end{abstract} \\ ${ }^{7}$ IdisNA, Instituto de Investigación Sanitaria de Navarra, Pamplona, Spain
}

\section{OPEN ACCESS}

Edited by:

Frederic Sampedro,

Sant Pau Institute for Biomedical

Research, Spain

Reviewed by:

Saul Martinez-Horta,

Hospital de la Santa Creu i Sant Pau,

Spain

Asuncion Avila

Hospital of Sant Joan Despi Moisès

Broggi, Spain

Juan Marín-Lahoz,

Hospital Universitario Miguel

Servet, Spain

*Correspondence:

María Cruz Rodríguez-Oroz mcroroz@unav.es

Specialty section:

This article was submitted to Movement Disorders,

a section of the journal

Frontiers in Neurology

Received: 30 June 2021 Accepted: 28 September 2021 Published: 05 November 2021

Citation

Martín-Bastida $A$ Delgado-Alvarado M

Navalpotro-Gómez I and Rodríguez-Oroz MC (2021) Imaging Cognitive Impairment and Impulse Control Disorders in Parkinson's Disease. Front. Neurol. 12:733570. doi: 10.3389/fneur.2021.733570
Dementia and mild forms of cognitive impairment as well as neuropsychiatric symptoms (i. e., impulse control disorders) are frequent and disabling non-motor symptoms of Parkinson's disease (PD). The identification of changes in neuroimaging studies for the early diagnosis and monitoring of the cognitive and neuropsychiatric symptoms associated with Parkinson's disease, as well as their pathophysiological understanding, are critical for the development of an optimal therapeutic approach. In the current literature review, we present an update on the latest structural and functional neuroimaging findings, including high magnetic field resonance and radionuclide imaging, assessing cognitive dysfunction and impulse control disorders in PD.

Keywords: impulse control disorders (ICD), Parkinson's disease dementia (PDD), mild cognitive impairment (MCl), magnetic resonance imaging (MRI), positron emission tomography (PET), single photon computed tomography (SPECT)

\section{INTRODUCTION}

Parkinson's disease (PD) is the second most common neurodegenerative disease in the world. Formerly considered to predominately be a movement disorder caused by the degeneration of dopaminergic neurons of the substantia nigra pars compacta $(\mathrm{SNc})(1,2)$. PD is now accepted to also present with non-motor features as part of the clinical manifestations. Among them, cognitive decline and neuropsychiatric alterations are highly debilitating and frequent.

In fact, the risk of developing dementia is about six times higher in PD patients than in age-andgender matched populations (3). Importantly, within the first 10 years of $\mathrm{PD}$ progression, dementia appears in more than $50 \%$ of patients (4), reaching up to $80 \%$ in the long-term $(3,5)$. Furthermore, mild cognitive impairment is highly prevalent in PD (PD-MCI) (mean 26.7\%; range 18.9-38.2\%) (6-9) and is a risk factor for the development of dementia (PDD) (10). Longitudinal studies have revealed that the conversion to dementia occurs in roughly $25-50 \%(6,11)$ of PD-MCI patients within 5 years.

The pathological basis of PDD is multifactorial, as demonstrated in post-mortem and clinical studies (12). For example, studies have reported dopaminergic neurodegeneration within the medial areas of the SNc, ventral tegmentum areas, and fronto-limbic areas (13), and neurotransmitter dysfunction in the cholinergic projections from the nucleus basalis of Meinert 
as well as in the serotoninergic and noradrenergic efferent fibres from the raphe nucleus and locus coeruleus, which play an important role in cognitive dysfunction (14-16). Furthermore, alpha-synuclein deposition in the form of Lewy bodies and Lewy neuritis spreading to the amigdalar complex, hippocampus, fusiform gyrus and temporal cortex along with synergistic Alzheimer's disease $(\mathrm{AD})$ pathology with beta-amyloid plaques and phosphorylated tau (neurofibrillary tangles) (17) are also critical in the pathogenesis of the cognitive decline.

Apart from cognitive impairment, psychiatric conditions are also common in PD, affecting the majority of patients during the course of the illness. The most frequent and problematic are affective disorders (depression and anxiety), psychosis (mainly visual hallucinations), apathy, and impulse control disorders (ICDs) (18). The most common ICDs experienced by PD patients include pathological gambling, binge eating, hypersexuality, and compulsive shopping, as well as other impulsive-compulsive behaviours (ICBs), such as punding, hobbyism or walkabout. To further complicate matters, approximately $14-17 \%$ of PD patients treated with dopaminergic replacement therapy, in particular with dopaminergic agonists (DA), may develop ICDs (19) although the cumulative incidence can be much higher (over 46\%) (20) ICDs often result in devastating financial, legal, or psychosocial problems (19). Unfortunately the management of these behaviours, which typically involves reducing DA treatment, can be challenging and often carries the risk of motor worsening or the development of DA withdrawal syndrome (21).

The development of neuroimaging techniques, including high field structural and functional magnetic resonance (MRI) and nuclear imaging, using positron emission tomography (PET) and single photon emission computed tomography (SPECT), helps in the diagnosis and monitoring of the motor and cognitive impairments associated with PD. Furthermore, neuroimaging can be used to shed light on the underlying pathophysiological aspects of cognitive impairment and neuropsychiatric manifestations, which in turn are associated with high levels of patient disability and morbidity.

In the current review, and for the sake of brevity, we will focus on cognitive decline and ICDs in patients with PD. To this end, we conducted a literature review of existing functional and structural imaging studies in cognitive dysfunction and ICD in PD. We performed a thorough search of the PubMed database selecting for English language articles containing "Parkinson's disease dementia," "mild cognitive impairment," "impulse control disorders," "imaging," "PET," and "MRI" published up until the 15th of March, 2021. The abstracts were screened for relevance, and carefully read if they were suitable. This review highlights the imaging modalities that detect consistent brain changes associated with cognitive impairment and ICD in PD.

\section{COGNITIVE IMPAIRMENT AND DEMENTIA}

\section{Magnetic Resonance Imaging Grey Matter}

Grey matter (GM) abnormalities have been the focus of numerous MRI studies in PD. Methodological approaches have substantially changed over the years. Analytical tools did only allow for regions of interest (ROIs) approach in early studies, which consisted of delineating certain brain areas, measuring their volume, and comparing them among different groups. This approach has been clearly overtaken by whole-brain approaches, which are able to disclose differences in GM volume without an a priori hypothesis. There are two main techniques, voxelbased morphometry (VBM) and surface-based analyses (SBA), both of them widely used in current studies. Whereas VBM measures GM volume, SBA is able to measure cortical thickness. As compared to VBM, cortical thickness is more sensitive to cortex changes, possibly because it is less dependent on cortical folding and the overall brain size (22). In the present review, we only include VBM and SBA studies (see Table 1).

Early whole-brain studies found higher levels of atrophy in PDD and PD-MCI patients compared to their cognitively normal counterparts (PD-NC) and control subjects [for review see (70, 71)], particularly in the parietal, occipital, mesial temporal, and frontal lobes, as well as in the hippocampus, amygdala, caudate, putamen, thalamus and substantia innominata. Furthermore, compared to PD-MCI patients, PDD patients exhibit GM reductions in the temporal and prefrontal areas (25), the amygdala (26), the anterior cingulate, the entorhinal and orbitofrontal cortices as well as in the parahippocampus, temporal pole, precuneus, and fusiform and lingual areas (28). A recent meta-analysis of voxel based morphometry (VBM) studies found that PD-MCI patients exhibited greater atrophy in the left anterior insula compared to PD-NC patients (35). However, PD$\mathrm{MCI}$ is a heterogeneous clinical entity in which one or several cognitive domains may be affected. Therefore, the focus of the field over the last few years has been to elucidate what type of PD-MCI confers a higher risk of progression to dementia. Most studies in PD-MCI patients, who were prospectively followed and classified according to conversion (or not) to PDD, found that frontal atrophy was associated with conversion to dementia $(36,72,73)$. In fact, PD-MCI patients who converted to dementia in $<3$ (36) or 4 years (37) had greater widespread atrophy and cortical thinning in the frontal, insular, and left middle temporal lobes at baseline than non-converters, with frontal lobe atrophy being the strongest predictor of progression to dementia (37). These findings were reinforced by a cross-sectional study showing that patients who developed PD-MCI within 2 years of diagnosis exhibited greater atrophy in the superior frontal gyrus than those with later cognitive decline (40). In addition, longitudinal studies in PD-NC patients who converted to PDMCI patients over time showed greater GM atrophy in the frontal, parietal, and temporal areas (32), as well as in the insular cortex and caudate nucleus $(29,32,39)$. Overall, the presence of frontal lobe atrophy seems to be a good predictor for cognitive decline in both PD-MCI to PDD and PD-NC to PD-MCI patients, which in turn is associated with lower cognitive scores on frontal/executive, language, and memory domains (7, 72-74).

Alzheimer's disease (AD)-related pathology is also present in cognitively impaired PD patients, specifically of the amnestic type (75). In fact, the presence of AD-related atrophy, such as hippocampal atrophy, has been described in PD patients with cognitive impairment. Previous studies have found increased hippocampal and entorhinal cortex atrophy in PDD patients 
TABLE 1 | Magnetic resonance imaging studies of cognitive impairment or dementia in Parkinson's disease.

\begin{tabular}{|c|c|c|c|c|}
\hline References & Population & $\begin{array}{l}\text { Radioligand and } \\
\text { technique }\end{array}$ & State & Main results/findings \\
\hline \multicolumn{5}{|l|}{ Grey matter imaging } \\
\hline Camicioli et al. (23) & $\begin{array}{l}\text { PD-MCl } \\
\text { PD-NC }\end{array}$ & VBM & Resting & $\begin{array}{l}\downarrow \text { hippocampus (AD }<\text { PD-NC }<\text { PDD }<\mathrm{HC}) \\
\downarrow \text { left hippocampus correlated with recognition memory and MMSE }\end{array}$ \\
\hline Brück et al. (24) & PD-NC & VBM & Resting & $\begin{array}{l}\downarrow \text { hippocampus and prefrontal }(\mathrm{PD}<\mathrm{HC}) \\
\downarrow \text { left hippocampus correlated with verbal memory } \\
\downarrow \text { prefrontal atrophy correlated with sustained attention tests }\end{array}$ \\
\hline Song et al. (25) & $\begin{array}{l}\text { PD-MCl } \\
\text { PDD } \\
\text { PD-NC }\end{array}$ & VBM & Resting & $\begin{array}{l}\downarrow \text { bilateral temporal, left prefrontal, insular, right occipital (PDD }<\text { PD-MCl }<\mathrm{HC} \text { ) } \\
\downarrow \text { right parietal, middle frontal, insular, striatum (PDD }<\text { PD-MCl }<\text { PD-NC) } \\
\downarrow \text { PCC correlated with disease duration in PDD }\end{array}$ \\
\hline Choi et al. (26) & $\begin{array}{l}\text { PDD } \\
\text { PD-MCl } \\
\text { PD-NC }\end{array}$ & VBM & Resting & $\begin{array}{l}\downarrow \text { substantia innominata (PDD > PD-MCl and PD-NC) } \\
\downarrow \text { substantia innominata correlates with MMSE, attention and object naming } \\
\text { domains. }\end{array}$ \\
\hline Beyer et al. (27) & $\begin{array}{l}\text { PD-MCl } \\
\text { PD-NC }\end{array}$ & VBM & Resting & $\begin{array}{l}\downarrow \text { hippocampal volume (CA1, CA3 and subiculum area) (PD-MCI, PD-NC }<\mathrm{HC}) \\
\downarrow \text { hippocampal volume correlated with CVLT-2 delayed free recall } \\
\downarrow \text { right hippocampal CA1 and subicular region correlated with CVLT-2 } \\
\text { recognition score }\end{array}$ \\
\hline $\begin{array}{l}\text { Pagonabarraga et } \\
\text { al. (28) }\end{array}$ & $\begin{array}{l}\text { PDD } \\
\text { PD-NC }\end{array}$ & SBA & Resting & $\begin{array}{l}\downarrow \text { parietal, temporal, occipital areas (PDD < PD-MCl < PD-NC) } \\
\downarrow \text { temporal correlated with attentional and language deficits } \\
\downarrow \text { occipital correlated with attentional, memory and language deficits. }\end{array}$ \\
\hline Lee et al. (29) & $\begin{array}{l}\text { PDD } \\
\text { PD-MCl } \\
\text { PD-NC }\end{array}$ & VBM & $\begin{array}{l}\text { Resting } \\
\text { (Longitudinal) }\end{array}$ & $\begin{array}{l}\downarrow \text { left prefrontal, left insular and CN (PDD converters < PD-MCl no converters) } \\
\text { PDD converters associated with } \downarrow \text { executive function, verbal memory, visual } \\
\text { recognition memory }\end{array}$ \\
\hline Filoteo et al. (30) & PD-NC & VBM & Resting & $\begin{array}{l}\downarrow \text { medial temporal and frontostriatal areas correlated with memory deficits } \\
\downarrow \text { frontostriatal volumes correlated with executive function } \\
\downarrow \text { frontal and occipital volumes with visuospatial function }\end{array}$ \\
\hline Kandiah et al. (31) & PD-NC & VBM & $\begin{array}{l}\text { Resting } \\
\text { (longitudinal) }\end{array}$ & $\downarrow$ Hippocampal volume is a risk factor for PD-MCl and PDD \\
\hline Wen et al. (32) & PD-NC & VBM & $\begin{array}{l}\text { Resting } \\
\text { (longitudinal) }\end{array}$ & $\begin{array}{l}\downarrow \text { frontal areas in PDD converters } \\
\downarrow \text { frontal and parietal areas associated with global cognitive scrores }\end{array}$ \\
\hline Foo et al. (33) & $\begin{array}{l}\mathrm{PD}-\mathrm{NC} \\
\mathrm{PD}-\mathrm{MCl}\end{array}$ & VBM & $\begin{array}{l}\text { Resting } \\
\text { (longitudinal) }\end{array}$ & $\begin{array}{l}\downarrow \text { right hippocampus at baseline }(\mathrm{PD}-\mathrm{MCl}<\mathrm{HC}) \\
\downarrow \text { baseline right } \mathrm{CA} 1 \text { correlated with attention } \\
\downarrow \mathrm{CA} 2 \text {-3 at follow-up correlated with episodic memory in PDD converters }\end{array}$ \\
\hline Low et al. (34) & PD-NC & SBA & $\begin{array}{l}\text { Resting } \\
\text { (longitudinal) }\end{array}$ & $\begin{array}{l}\downarrow \text { global hippocampal at baseline predicted PDD } \\
\downarrow \text { subiculum and fimbria volume correlated with attention and executive functions }\end{array}$ \\
\hline Zheng et al. (35) & $\begin{array}{l}\text { PD-MCl } \\
\text { PDD } \\
\text { PD-NC }\end{array}$ & VBM & $\begin{array}{l}\text { Resting } \\
\text { (meta-analysis) }\end{array}$ & $\downarrow$ left anterior insula in PD-MCl < PD-NC (predictor) \\
\hline Gasca-Salas et al. (36) & $\begin{array}{l}\mathrm{PD}-\mathrm{NC} \\
\mathrm{PD}-\mathrm{MCl}\end{array}$ & SBA & $\begin{array}{l}\text { Resting } \\
\text { (meta-analysis) }\end{array}$ & $\begin{array}{l}\uparrow \text { thinning in bilateral frontal, insular and left middle temporal areas (PD-MCl } \\
\text { converters > PD-MCl non-converters > controls) }\end{array}$ \\
\hline Chung et al. (37) & $\begin{array}{l}\text { PD-MCl } \\
\text { PDD } \\
\text { PD-NC }\end{array}$ & SBA & Resting & $\begin{array}{l}\uparrow \text { thinning from posterior cortical area to frontal cortex (PDD converters > PDD } \\
\text { non-converters) } \\
\uparrow \text { thinning in right medial superior frontal and olfactory cortices distinguishes } \\
\text { PDD converters from PDD non-converters. }\end{array}$ \\
\hline Xu et al. (38) & PD-NC & VBM & $\begin{array}{l}\text { Resting } \\
\text { (longitudinal) }\end{array}$ & $\begin{array}{l}\downarrow \text { bilateral hippocampal at baseline (PD-NC }<\mathrm{HC} \text { ) correlated with MMSE } \\
\downarrow \text { bilateral CA4, ML, GC-DG subfields, and left CA2/3 and right presubiculum } \\
\text { subfields at follow-up (PD-MCI }<\text { PD-NC) correlated with MMSE and MOCA. } \\
.\end{array}$ \\
\hline Zhou et al. (39) & $\begin{array}{l}\text { PD-MCl } \\
\text { PDD }\end{array}$ & VBM & $\begin{array}{l}\text { Resting } \\
\text { (longitudinal) }\end{array}$ & $\begin{array}{l}\downarrow \text { right temporal at baseline and left temporal and frontal lobe at follow-up (PDD } \\
\text { converters }<\text { non-converters) }\end{array}$ \\
\hline Donzuso et al. (40) & $\begin{array}{l}\text { PD-MCl } \\
\text { PD-NC }\end{array}$ & VBM & Regional & $\begin{array}{l}\downarrow \text { frontal gyrus, precuneus, angular gyrus, temporal lobe and cerebellum (PD-MCl } \\
<\mathrm{HC} \text { ) } \\
\downarrow \text { frontal gyrus correlated with RCPM } \\
\downarrow \text { precuneus correlated with accuracy of Barrage } \\
\downarrow \text { Inferior frontal gyrus with Stroop test. }\end{array}$ \\
\hline \multicolumn{5}{|l|}{ White matter imaging } \\
\hline Kamagata et al. (41) & $\begin{array}{l}\text { PDD } \\
\text { PD-NC }\end{array}$ & DTI & Resting & $\begin{array}{l}\downarrow \text { FA in prefrontal white matter and genu of corpus callosum (PDD < PD-NC) } \\
\downarrow \text { FA in prefrontal white matter and genu of corpus correlated with MMSE }\end{array}$ \\
\hline
\end{tabular}


TABLE 1 | Continued

\begin{tabular}{|c|c|c|c|c|}
\hline References & Population & $\begin{array}{l}\text { Radioligand and } \\
\text { technique }\end{array}$ & State & Main results/findings \\
\hline Hattori et al. (42) & $\begin{array}{l}\text { PDD } \\
\text { DLB } \\
\text { PD-NC }\end{array}$ & DTI & Resting & $\begin{array}{l}\downarrow \text { FA in bilateral in SLF; ILF, IFO, UNF, CIN, INC, CCA, CRA (DLB, PDD, PD-MCl } \\
<\text { PD-NC and controls) } \\
\downarrow \text { FA in parietal WM areas with MMSE }\end{array}$ \\
\hline Deng et al. (43) & $\begin{array}{l}\text { PDD } \\
\text { PD-MCl } \\
\text { PD-NC }\end{array}$ & DTI & Resting & $\begin{array}{l}\downarrow \text { FA left frontal and right temporal WM (PDD, PD-MCI < PD-NC) } \\
\downarrow \text { FA left AC and CC splenium correlated with disease duration }\end{array}$ \\
\hline Meltzer et al. (44) & $\begin{array}{l}\text { PDD } \\
\text { PD-MCl } \\
\text { PD-NC }\end{array}$ & DTI & Resting & $\begin{array}{l}\downarrow F A \text { and } \uparrow \text { MD in SLF, IFU, UNF and corpus callosum (PDD , PD-NC < HC) } \\
\downarrow \text { FA in anterior WM tracts correlated with executive function } \\
\uparrow \mathrm{MD} \text { in anterior WM tracts correlated with global cognition deficits }\end{array}$ \\
\hline Agosta et al. (45) & $\begin{array}{l}\text { PD-MCl } \\
\text { PD-NC }\end{array}$ & DTI & Resting & $\downarrow \mathrm{FA}$ in SFO, IFO UNF, genu and body of CC (PD-MCI < HC) \\
\hline Auning et al. (46) & $\begin{array}{l}\mathrm{PD}-\mathrm{MCl} \\
\mathrm{PD}-\mathrm{NC} \\
\mathrm{AD}\end{array}$ & DTI & Resting & $\begin{array}{l}\downarrow \mathrm{FA} \text { in WM of temporal-parietal tracts (PD-MCI }<\mathrm{HC} \text { ). No differences PD-MCI vs } \\
\text { AD. } \\
\downarrow \text { FA in WM prefrontal tracts with executive and visuospatial deficits. }\end{array}$ \\
\hline Chen et al. (47) & $\begin{array}{l}\text { PDD } \\
\text { PD-NC }\end{array}$ & DTI & Resting & $\begin{array}{l}\downarrow \text { FA left hippocampus (PDD < PD-HC) } \\
\uparrow \mathrm{MD} \text { in SLF, SFO, UNF, genu of corpus callosum (PDD > PD-HC) } \\
\downarrow \text { FA in SLF, SFO and hippocampus correlated with MOCA }\end{array}$ \\
\hline Bledsoe et al. (48) & $\begin{array}{l}\text { PDD } \\
\text { PD-NC }\end{array}$ & DTI & Resting & $\begin{array}{l}\uparrow M D \text { and } A D \text { in anterior segments in CC (PDD > PD-NC) } \\
\uparrow M D \text { and } A D \text { in anterior CC associated with global and specific cognitive } \\
\text { domains in PDD. }\end{array}$ \\
\hline $\begin{array}{l}\text { Chondrogiorgi et al. } \\
\text { (49) }\end{array}$ & $\begin{array}{l}\text { PDD } \\
\text { PD-NC }\end{array}$ & DTI & Resting & $\begin{array}{l}\downarrow \text { FA body corpus callosum, cingulum, corona radiate (PDD }<\text { PD-NC) } \\
\downarrow \text { FA and } \uparrow M D \text { in limbic, prefrontal and CC tracts associated with PD-CRS }\end{array}$ \\
\hline Beyer et al. (50) & $\begin{array}{l}\text { PDD } \\
\text { PD-NC }\end{array}$ & WMH & Resting & $\begin{array}{l}\uparrow W M H \text { in deep WM and periventricular areas (PDD > PD-NC) } \\
\text { WMH is associated with MMSE }\end{array}$ \\
\hline Lee et al. (51) & $\begin{array}{l}\text { PDD } \\
\text { PD-NC } \\
\text { AD }\end{array}$ & WMC & Resting & $\begin{array}{l}\uparrow \mathrm{WMH} \text { in PDD > PD-NC } \\
\text { WMH correlated with UDPRS, MMSE and PD-CDR }\end{array}$ \\
\hline Joki et al. (52) & $\begin{array}{l}\text { PDD } \\
\text { DLB } \\
\text { PD-NC AD }\end{array}$ & WMC & Resting & $\uparrow \mathrm{WMH}$ in DLB and $\mathrm{AD}>\mathrm{PDD}>\mathrm{PD}-\mathrm{HC}$ and $\mathrm{HC}$ \\
\hline Huang et al. (53) & $\begin{array}{l}\text { PD-MCl } \\
\text { PD-NC }\end{array}$ & WM & Resting & $\begin{array}{l}\text { WHM burden associated with PD-MCI }(p<0.05) \text { besides the presence of } \mathrm{CV} \text { risk } \\
\text { factors } \\
\text { Periventricular WMH burden associated with executive function and visuospatial } \\
\text { function }\end{array}$ \\
\hline \multicolumn{5}{|l|}{ Functional MRI } \\
\hline Lewis et al. (54) & $\begin{array}{l}\text { PD-NC } \\
\text { PD-MCl }\end{array}$ & $\mathrm{fMRI}$ & $\begin{array}{l}\text { Working memory } \\
\text { task }\end{array}$ & $\begin{array}{l}\downarrow \text { activity of caudate nuclei during retrieval and manipulation. (PD-MCl }<\mathrm{PD}-\mathrm{NC} \text { ) } \\
\text { Underactivation of dorsolateral and ventrolateral prefrontal cortex and right } \\
\text { putamen }\end{array}$ \\
\hline Monchi et al. (55) & PD-MCl & $\mathrm{fMRI}$ & Card-sorting task & $\begin{array}{l}\downarrow \text { activity in tasks involving the caudate nucleus in DLPFC and VLPFC in PD } \\
\uparrow \text { activity in tasks that do not require the caudate nucleus in DLPFC and VLPFC, } \\
\text { premotor, posterior prefrontal }\end{array}$ \\
\hline Seibert et al. (56) & $\begin{array}{l}\text { PDCN } \\
\text { PDD }\end{array}$ & $\mathrm{fMRI}$ & Resting & No differences in FC of the DMN (PD-NC = PDD) \\
\hline Baggio et al. (57) & $\begin{array}{l}\text { PDCN } \\
\text { PD-MCl }\end{array}$ & $\mathrm{fMRl}$ & Resting & $\begin{array}{l}\downarrow \text { connectivity in long-range connections and increased local } \\
\text { interconnectedness (PD-MCl < PD-NC) }\end{array}$ \\
\hline Lebedev et al. (58) & PD & $\mathrm{fMRl}$ & Resting & $\begin{array}{l}\text { Executive impairment associated with altered balance between cortical and } \\
\text { subcortical processing at rest }\end{array}$ \\
\hline Amboni et al. (59) & $\begin{array}{l}\mathrm{PD}-\mathrm{MCl} \\
\mathrm{PD}-\mathrm{CN}\end{array}$ & $\mathrm{fMRI}$ & Resting & $\begin{array}{l}\downarrow \text { FC of bilateral prefrontal cortex within left F-P network (PD-MCl < PD-NC). } \\
\text { Positive correlation between visuospatial function Z score and left prefrontal } \\
\text { cortex ICA z score. }\end{array}$ \\
\hline Baggio et al. (60) & $\begin{array}{l}\text { PD-MCl } \\
\text { PDCN }\end{array}$ & $\mathrm{fMRI}$ & Resting & $\begin{array}{l}\downarrow \text { FC of the DAN with widespread, right sided, frontal/insular areas, thalami and } \\
\text { left striatum (PD-MCl }<\mathrm{HC}) \text {. } \\
\downarrow \text { FC less extensive, and regions of DAN itself and of the right FPN. (PD-MCl }< \\
\text { PD-CN) }\end{array}$ \\
\hline Gorges et al. (61) & $\begin{array}{l}\mathrm{PDCN} \\
\mathrm{PD}-\mathrm{MCl}\end{array}$ & $\mathrm{fMRl}$ & Resting & $\begin{array}{l}\downarrow \text { intrinsic FC within the DMN, the motor network, and the DAN (PD-MCl }<\mathrm{HC} \text { ) } \\
\downarrow \text { intrinsic FC preferentially in the DMN, but also in the motor, DAN, VAN, and } \\
\text { basal ganglia-thalamic intrinsic functional networks (PD-MCI }<\text { PD-CN) }\end{array}$ \\
\hline
\end{tabular}


TABLE 1 | Continued

\begin{tabular}{|c|c|c|c|c|}
\hline References & Population & $\begin{array}{l}\text { Radioligand and } \\
\text { technique }\end{array}$ & State & Main results/findings \\
\hline Shin et al. (62) & $\begin{array}{l}\text { PDCN } \\
\text { PD-MCI } \\
\text { (early/late) }\end{array}$ & $\mathrm{fMRI}$ & fResting & $\begin{array}{l}\downarrow \text { FC in parahippocampal gyrus, DLPC temporal, and precuneus; } \uparrow \text { FC in the } \\
\text { inferior frontal, primary motor, and occipital areas (PD-MCl early vs PD-CN) } \\
\downarrow \text { in the medial frontal areas andcingulate cortex and } \uparrow \text { FC in the parietal and } \\
\text { occipital areas (PD-MCl (longer) vs PD-CN) }\end{array}$ \\
\hline Chen et al. (63) & $\begin{array}{l}\text { PDCN } \\
\text { PD-MCl }\end{array}$ & fMRI & Resting & $\begin{array}{l}\downarrow \text { in PCC-prefrontal cortex, left parieto-occipital juntion, and right temporal gyrus } \\
\text { (PD-MCl }<\text { PD-CN) } \\
\downarrow \text { PCC- left inferior temporal gyrus, hippocampus, inferior parietal lobules and } \\
\text { PCC/precuneus (PD-MCl <. HC) }\end{array}$ \\
\hline Bezdicek et al. (64) & $\begin{array}{l}\text { PD-CN } \\
\text { PD-MCl }\end{array}$ & $\mathrm{fMRI}$ & Resting & $\begin{array}{l}\downarrow \text { FC in bilateral superior parietal lobule and precuneus (PD-MCl }<\text { PDCN) } \\
\downarrow \text { interconnectedness of the lentiform nuclei and midcingulate cortex, } \\
\text { precuneus, the superior parietal cortex and extended portions of the } \\
\text { temporoparietal associative cortex bilaterally (PD-MCl }<\mathrm{HC} \text { ) }\end{array}$ \\
\hline Diez-Cirada et al. (65) & $\begin{array}{l}\text { PDCN } \\
\text { PD-MCl } \\
\mathrm{HC}\end{array}$ & $\mathrm{fMRI}$ & Resting & $\begin{array}{l}\text { No differences (PD-MCI vs. PDCN) } \\
\downarrow \text { internetwork FC between the somatomotor and cognitive control networks, } \\
\text { somatomotor and visual networks, somatomotor and auditory networks, } \\
\text { cognitive control and visual and subcortical and DMN (PD-MCl < HC). }\end{array}$ \\
\hline Hou et al. (66) & $\begin{array}{l}\text { PD-MCl } \\
\text { PD-NC }\end{array}$ & $\mathrm{fMRI}$ & Resting & $\downarrow$ activity betweem DMN and prefrontal cortex (PD-MCI < PD-CN) \\
\hline Wolters et al. (67) & $\begin{array}{l}\text { PDD } \\
\text { PD-MCl } \\
\text { PD-NC }\end{array}$ & $\mathrm{fMRI}$ & $\begin{array}{l}\text { Resting } \\
\text { (meta-analysis) }\end{array}$ & $\downarrow$ activity in Dorsomedial prefrontal cortex (within the DMN) in PD-MCl \\
\hline Fathy et al. (68) & $\begin{array}{l}\text { PD-MCl } \\
\text { PD-NC }\end{array}$ & $\mathrm{fMRI}$ & Resting & $\begin{array}{l}\downarrow \text { FC of DMN and dorsal anterior insula associated with cognitive performance in } \\
\text { PD. } \\
\downarrow \text { connectivity between } \mathrm{dAl} \text { and ACC was associated with reduced CAMCOG } \\
\text { scales }\end{array}$ \\
\hline Pan et al. (69) & $\begin{array}{l}\text { PD-MCl } \\
\text { PD-NC }\end{array}$ & $\mathrm{fMRI}$ & Resting & $\begin{array}{l}\uparrow \mathrm{FC} \text { between } \mathrm{dAl} \text { and superior parietal gyrus (PD-MCI vs PD-NC) correlated with } \\
\text { memory and executive tests } \\
\uparrow \mathrm{FC} \text { between dAl and cingulated gyrus (PD-MCl vs } \mathrm{HC} \text { ) correlated with } \\
\text { attention/working memory, visuospatial function, and language }\end{array}$ \\
\hline
\end{tabular}

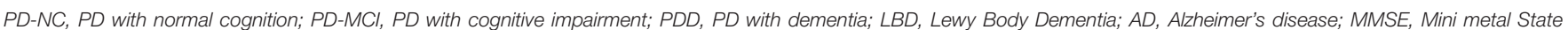

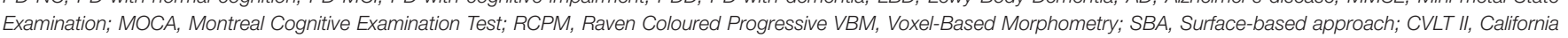

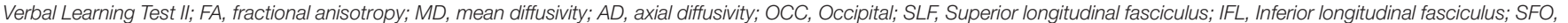

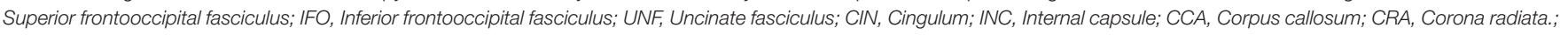

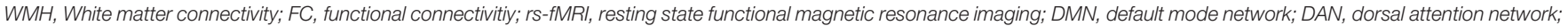
VAN, ventral attention network,; DLPFC, dorsolateral prefrontal cortex; VLPDF, ventrolateral prefrontal cortex; CAMCOG, Cambridge Cognition Examination.

compared to non-demented patients $(70,71)$, which was associated with memory impairment $(24,27,30)$. In addition, reduced hippocampal volume has been associated with the development of PD-MCI and PDD in longitudinal studies (29, $31,76)$. Recent advances in analytical imaging procedures have allowed the analysis of hippocampal subfields volume, indicating that the atrophy of some regions might confer higher risk of dementia $(33,34,38)$.

The association of certain gene variants and cognition and their influence on structural changes have been assessed in some studies. Among genes associated with PD, glucocerebrosidase (GBA) mutations confer the highest risk of dementia. PD patients with GBA mutations as compared to those without GBA mutations experienced a more rapid motor and cognitive decline together with a greater, earlier and faster cortical thinning in posterior parieto-occipital regions as well as frontal and orbito-frontal cortices as demonstrated in longitudinal study (77). The catechol O-methyltransferase (COMT) Val158Met polymorphism has also been associated with cognitive decline. It has been recently shown that $\mathrm{PD}$ patients harbouring the
Val/Val genotype had widespread reduction in GM, including fronto-subcortical and parieto-temporal territories (78). Finally, microtubule-associated protein tau (MAPT) $\mathrm{H} 1 / \mathrm{H} 1$ genotype is considered a risk factor for taupathies in addition to cognitive dysfunction in PD. In an interesting study from Sampedro et al. (79) cross-sectional and longitudinal GM reductions in parietotemporal areas were found in PD patients with homozygous for MAPT H1 compared to PD patients not harbouring this genetic mutation.

In summary, GM atrophy occurs in the early stages of cognitive decline in $\mathrm{PD}$, and steadily increases along with the progression of cognitive deficits, before broadly affecting the cortical and subcortical areas in the dementia stage. Therefore, atrophy in frontal areas and certain hippocampal subfields might lead to the development of dementia in PD and should be considered as a potential biomarker.

\section{White Matter}

Several studies have shown that fractional anisotropy (FA) is reduced and mean diffusivity $(\mathrm{MD})$ is increased in the main 
white matter (WM) tracts (the superior and inferior longitudinal, inferior fronto-occipital, cingulate and uncinated fasciculi, and the anterior limb of the internal capsule) of PDD patients compared to PD-NC patients or controls [for review see (70, 71)]. Similarly, PD-MCI patients exhibit less FA than PD-NC patients or controls in the inferior fronto-occipital and uncinate fasciculi corpus callosum as well as the corona radiate (4245,80 ). Interestingly, a previous longitudinal study observed higher widespread MD in patients with PD-MCI than in those with PD-NC at 18 months follow-up (81), which correlated with lower executive and attention cognitive scores. It has been suggested that WM alterations conveying a cortical-subcortical disconnection may precede GM changes in PD patients during the process of cognitive decline. Indeed, Hattori et al. found prominent WM changes in both PDD and PD-MCI patients, while concurrent GM changes were only observed in subjects with PDD (42).

The role of WM tracts in cognition is further supported by several studies reporting correlations between cognitive functions and WM abnormalities in PD-NC patients. In fact, global cognition has been shown to be correlated with low FA values in the superior and inferior longitudinal fasciculi, the inferior fronto-occipital fasciculus, the corpus callosum, the uncinated fasciculus, and the cingulum $(41,47,82,83)$. Furthermore, impairments in executive function have been consistently found to be associated with WM abnormalities in the frontal and parietal regions $(46,48,49,84)$.

Another, seemingly more imprecise, way of assessing WM integrity is detecting the presence of WM hyperintensities (WMHs), which has yielded heterogeneous results. For example, several longitudinal studies did not find any significant differences in WMHs between PD-MCI, PDD and PD-NC patients $(51,85,86)$ or any association between WMHs and clinically relevant cognitive decline in studies (86). However, others studies have reported greater deep WMHs and periventricular WMHs in PDD patients compared to PD-NC patients (50-52) and in PD-MCI to PD-NC patients ( 68).

In summary, WM integrity is disrupted in the main tracts in PD-MCI and PDD patients. These changes might precede GM atrophy suggesting that abnormalities within key WM tracts may be the first structural changes resulting in functional asynchrony of interconnected brain regions devoted to cognitive function. The value of several WM related metrics, such as FA and MD, in the early diagnosis of cognitive decline deserve further attention.

\section{Functional MRI}

Functional connectivity (FC) studies assess regional activation of the brain or the level of dependency between two or several anatomic locations through functional MRI (fMRI) in resting state or with the execution of experimental paradigms. The default mode network (DMN) symmetrically involves the medial prefrontal cortex, precuneus, posterior cingulate gyrus, inferior parietal lobes, and lateral temporal cortices (87) and is activated during cognitively demanding tasks requiring higherorder conceptual representations (87). It is the most studied resting-state network in $\mathrm{PD}$, showing enhanced activity during rest and decreased activity during experimental tasks.
Importantly, there is a clear direct association between DMN activity and cognition in PD. For example, a restingstate fMRI study (88) found that PD-NC patients displayed a positive correlation between the connectivity of their right medial temporal lobe and the DMN in the context of memory performance, as well as between the inferior parietal cortex and the DMN in visuospatial performance. A recent meta-analysis found that cognitive impairment in PD was associated with brain FC alterations, predominantly in the DMN (67). Studies in PDMCI patients have also revealed functional hypoconnectivity of the DMN $(61-63,89,90)$, which was positively associated with global cognitive function $(63,68,91,92)$. Interestingly, DMN connectivity with the occipital and posterior parietal cortical regions was found to be increased in PD-MCI patients (60), which in turn was correlated with visuospatial performance and occipital-parietal cortical thinning (57). Findings from other studies suggest that DMN connectivity abnormalities can be used to characterise PD patients, regardless of their cognitive status $(66,93)$, and that other resting-state networks, such as the fronto-parietal network (FPN), are more specifically linked to PD-MCI (59). Nevertheless, abnormalities in other resting-state networks, such as in the sensorimotor network (SMN) $(65,89)$, the ventral attention network (VAN) (94), the dorsal attention network (DAN) (64), and the salience network (SN) (69) have been found to be associated with PD-MCI, and with low cognitive performance in PD patients $(54,58,95)$. However, differences in pre-processing and analysis methods as well as in the PD-MCI criteria may explain the heterogeneity of these results.

Importantly, fMRI task-based studies have shown that PDNC patients demonstrate weaker recruitment of several areas, including the anterior cingulate cortex, caudate, putamen, and left precentral gyrus as well as the medial, dorsolateral and ventrolateral prefrontal cortices during working memory or executive function tasks $(55,96,97)$. However, those changes are also found in PD-MCI patients, hence they may be associated with the presence of executive dysfunction (54).

Recognition memory is typically impaired in patients with dementia (98). fMRI while performing a verbal memory paradigm PD patients showed a weaker deactivation than controls in the inferior orbitofrontal and temporal cortices that correlated with verbal recognition memory (99).

In conclusion, an altered pattern of resting FC in the DMN seems to be associated with cognitive impairments in PD, which in turn is associated with posterior cortical cognitive deficits that eventually progress to dementia. Functional brain changes might precede structural abnormalities and thus, the value of fMRI in early diagnosis is a promising tool to be considered in further studies.

\section{Nuclear Imaging Brain Glucose Metabolism}

Several [18F] fluoro-D-glucose ([18F]FDG) PET studies with PD-MCI patients show reduced frontal, temporoparietal, occipital and precuneal metabolism as well as the caudate nucleus compared to healthy controls, and in less degree to PD-NC (100-104), being regional hypometabolic changes more 
marked in multi-domain PD-MCI patients than in singledomain (103). Furthermore, extensive areas of hypometabolism, mostly affecting the posterior cortical regions, including the parieto-occipital, associative parietal, and inferior temporal cortices (102) and to a lesser degree, the striatum and prefrontal cortex $(101,104,105)$, have been observed in PDD patients when compared to controls, PD-NC and PD-MCI (see Table 2).

Several longitudinal studies have assessed the progression of regional metabolic changes in $\mathrm{PD}$ with cognitive dysfunction (100, 107, 108). The aforementioned studies showed severe bilateral hypometabolism in parieto-occipital areas, especially within the visual association cortex (Broadman area 18) and posterior cingulate cortices (100), as well as the fusiform gyrus (107), predicting cognitive decline after more than 2 years follow up, thus heralding the conversion from PD-NC and PD-MCI to PDD.

The role of regional hypometabolism in cognition is further supported by several studies reporting correlations between memory and visuospatial functions in the posterior temporal and parietal regions and also with attentional, executive, and language functions in the frontal regions in patients with PD-MCI and PDD (101, 144). Furthermore, in a prospective study (145) found that the association between reduced regional metabolism in temporoparietal and occipital areas and the presence of visual hallucinations in linked with the conversion from $\mathrm{PD}-\mathrm{NC}$ to PDD.

Using voxel-based spatial covariance analysis of FDG imaging, previous studies described the presence of a $P D$ cognition-related pattern (PDCP) (106) consisting of hypometabolism in the medial prefrontal, premotor, precuneus, and parietal association areas. This pattern increased over time along with cognitive decline (146), and was associated with dopaminergic denervation in the nucleus caudate (116), as well as with executive and memory performance in PD-MCI patients (106). The expression of PDCP has been considered as a potential imaging biomarker for cognitive dysfunction in $\mathrm{PD}$, although its prognostic value is yet to be ascertained (147).

The relationship between cerebral metabolism and atrophy displays dissociable patterns along cognitive impairment in $\mathrm{PD}$, with regional hypometabolism preceding spatially matching structural atrophy areas (105). Thus, in PD-MCI patients, areas with hypometabolism exceed atrophy in the angular gyrus, occipital, orbital, and frontal lobes, however in PPD patients; these hypometabolic areas are replaced by atrophy and widespread cortical and subcortical reductions in metabolism is observed surrounding the atrophy areas. This indicates that there is a specific gradient of severity in cortical changes as cognitive dysfunction progresses in $\mathrm{PD}$, with atrophy lagging behind hypometabolism as the pathological stages continue.

In conclusion, changes in brain glucose metabolism are present at the early stages of cognitive impairment in PD with hypometabolism in posterior parieto-occipital areas in PD-MCI, which steadily extends to the frontal and subcortical areas in PDD. Hypometabolism in the posterior cortex may point to the development of dementia in $\mathrm{PD}$, representing an earlier step to grey matter atrophy.

\section{Dopamine}

Several studies have suggested that cognitive dysfunction in PD is partially based on striatal dopaminergic degeneration, which leads to dysfunction of the frontostriatal pathways (109, 110, 114, 115). In fact, studies have found that PDD and in less degree PDMCI patients have a greater striatal dopaminergic deficit than PD-NC patients, as assessed with either ${ }^{123}$ I Ioflupane FP-CIT SPECT $(110,114)$ or ${ }^{18}$ Flurodopa (F-Dopa) PET $(109,111)$.

In particular, higher dopaminergic denervation in the caudate nucleus has been found to be associated with dysfunction in working memory, attention, and verbal fluency (109, 112-114) in both PDD and PD-MCI patients. Importantly, the associative fronto-striatal circuitry (orbitofrontal and dorsolateral prefrontal cortices) is known to be modulated by caudate dopaminergic signalling in PD patients suffering from executive dysfunction (115). Dopamine transporter (DAT) binding in the caudate nucleus is associated with the expression of the PD-related cognitive pattern (PDCP) (116), highlighting the importance of nigral dopaminergic input in the caudate nucleus and its cognitive functioning in PD. According to previous studies, reduced DAT availability in the caudate nucleus may be used as a potential predictor of cognitive dysfunction in PD (148), but only when combined with other diagnostic biomarkers in a multiple regression analysis including $\operatorname{CSF}\left(\mathrm{A} \beta_{42}\right.$ to t-tau ratio) and non-motor clinical scales (Montreal Cognitive Assessment (MoCA) and University of Pennsylvania Smell Identification Test (UPSIT) scores).

Dopaminergic depletion in extrastriatal areas derived from mesocortical and mesolimbic projections is also involved in the cognitive dysfunction associated with PD. For example, previous studies have found that frontal areas, including the anterior cingulate cortex (ACC) and middle frontal gyrus as well as the caudate nucleus, displaying reduced dopaminergic F-dopa-PET uptake in patients with PDD $(109,111,112)$ when compared to PD-NC and controls. Moreover, the dopaminergic reduction in frontal areas shows inverse correlation with executive and attentional dysfunction in PDD (109).

Furthermore, the availability of post-synaptic dopaminergic D2 tracers such as ${ }^{11} \mathrm{C}$ Raclopride is found to be decreased along the mesolimbic and mesocortical areas in patients with PDD compared to PD-NC and controls (117). In contrast, reduced availability of D2 receptors is showed in bilateral insula, ACC and parahippocampal giry in patients with $\mathrm{PD}-\mathrm{MCI}$ when compared to PD-NC (118), being in turn associated with executive and memory deficits.

The relationship between striatal dopaminergic degeneration and cortical degeneration is of special interest in PD. In a multimodal study, Sampedro et al. (149) showed that dopaminergic loss in caudate nucleus in early stage PD patients as measured with DAT is associated with reduced cortical thickness in both frontal, temporal and posterior cortices in cross-sectional and longitudinal cohorts, which in turn are associated with neuropsychological deficits. Previous results are important to remark as reduced caudate DAT uptake as well as cortical thickness in temporo-parieto-occipital areas in PD-NC patients could potentially predict the conversion to PD-MCI (70). 
TABLE 2 | Radionuclide imaging studies of cognitive impairment or dementia in Parkinson's disease.

\begin{tabular}{|c|c|c|c|c|}
\hline Studies & Population & $\begin{array}{l}\text { Radioligand and } \\
\text { technique }\end{array}$ & State & Main results/findings \\
\hline \multicolumn{5}{|l|}{ Glucose metabolism } \\
\hline Huang et al. (106) & $\begin{array}{l}\mathrm{PD}-\mathrm{MCl} \\
\mathrm{PD}-\mathrm{NC}\end{array}$ & PET FDG & Resting & $\begin{array}{l}\downarrow \text { posterior cortical prefrontal and parietal (PD-MCl }<\text { PD-NC } \\
\uparrow \text { metabolism in brainstem and cerebellum (PD-MCl }>\text { PD-NC) } \\
\text { Expression of PDCP }(p>0.05)\end{array}$ \\
\hline Hosokai et al. (102) & $\begin{array}{l}\mathrm{PD}-\mathrm{MCl} \\
\mathrm{PD}-\mathrm{NC}\end{array}$ & PET FDG & Resting & $\begin{array}{l}\downarrow \text { posterior cortical regions (temporo-parieto-occipital junction) } \\
\text { (PD-MCl < PD-NC, HC) }\end{array}$ \\
\hline Pappatá et al. (104) & $\begin{array}{l}\mathrm{PD}-\mathrm{MCl} \\
\mathrm{PD}-\mathrm{NC}\end{array}$ & PET FDG & Resting & $\begin{array}{l}\downarrow \text { prefontal, parietal, associative cortices and striatum (PD-MCI }< \\
\text { PD-NC, HC) }\end{array}$ \\
\hline Bohnen et al. (100) & $\begin{array}{l}\text { PDD } \\
\text { PD-NC }\end{array}$ & PET FDG & $\begin{array}{l}\text { Resting } \\
\text { (Longitudinal) }\end{array}$ & $\begin{array}{l}\downarrow \text { caudate, occipital PCC and associative visual cortex (BA 18) in PDD } \\
<\text { PD-NC and HC) baseline. } \\
\downarrow \text { follow up at thalamus, PCC, occipital, parietal and frontal in (PDD }< \\
\text { PD-NC). }\end{array}$ \\
\hline García-García et al. (86) & $\begin{array}{l}\text { PDD } \\
\text { PD-MCl } \\
\text { PD-NC }\end{array}$ & PET FDG & Resting & $\begin{array}{l}\downarrow \text { frontal and parietal (PD-MCI < PD-NC); } \downarrow \text { arietal, temporal and } \\
\text { occipital (PDD }<\text { PD-MCl) } \\
\text { Executive function correlated with parieto-temporo-occipital and frontal } \\
\text { metabolism; memory correlated with temporo-parietal metabolism; } \\
\text { visuospatial correlated with parieto-temporo-occipital metabolism; } \\
\text { Language with frontal metabolism }\end{array}$ \\
\hline $\begin{array}{l}\text { González-Redondo et al. } \\
\text { (105) }\end{array}$ & $\begin{array}{l}\text { PDD } \\
\text { PD-MCl } \\
\text { PD-NC }\end{array}$ & $\begin{array}{l}\text { PET FDG } \\
\text { VBM }\end{array}$ & Resting & $\begin{array}{l}\downarrow \text { metabolism }>\text { atrophy in angular gyrus, occipital, orbital and frontal } \\
\text { lobes (PD-MCI > PDD) } \\
\downarrow \text { metabolism areas replaced by atrophy with widespread } \\
\text { hypometabolism (PDD > PD-MCl) }\end{array}$ \\
\hline Tard et al. (107) & $\begin{array}{l}\text { PDD } \\
\text { PD-NC }\end{array}$ & PET FDG & $\begin{array}{l}\text { Resting } \\
\text { (Longitudinal) }\end{array}$ & $\begin{array}{l}\downarrow \text { follow up metabolism bilateral precuneus, left temporal and fusiform } \\
\text { gyrus (PDD < PD-NC) }\end{array}$ \\
\hline Baba et al. (108) & $\begin{array}{l}\text { PDD } \\
\text { PD-MCl } \\
\text { PD-NC }\end{array}$ & PET FDG & $\begin{array}{l}\text { Resting } \\
\text { (Longitudinal) }\end{array}$ & $\begin{array}{l}\downarrow \text { follow up metabolism bilateral parieto-occipital cortices (PDD < } \\
\text { PD-MCl and PD-NC) }\end{array}$ \\
\hline \multicolumn{5}{|l|}{ Dopaminergic imaging } \\
\hline Rinne et al. (109) & PD-NC & $\begin{array}{l}\text { PET } \\
{\left[{ }^{18} \text { F]fluorodopa }\right.}\end{array}$ & Resting & $\begin{array}{l}\text { Put, } \mathrm{CN} \text { and Frontal cortex }(\mathrm{PD}<\mathrm{HC}) \\
\downarrow \text { FDOPA in CN correlated with Stroop interference task } \\
\downarrow \text { FDOPA in Frontal cortex correlated with digit span, verbal fluency and } \\
\text { recall tests. }\end{array}$ \\
\hline Walker et al. (110) & $\begin{array}{l}\text { PD-NC } \\
\text { DLB } \\
\text { AD }\end{array}$ & $\begin{array}{l}\text { SPECT } \\
{\left[{ }^{123} \text { I]FP-CIT }\right.}\end{array}$ & Resting & Put, CN (PD, DLB < AD, HC) \\
\hline Ito et al. (111) & $\begin{array}{l}\text { PD-NC } \\
\text { PDD }\end{array}$ & $\begin{array}{l}\text { PET } \\
{\left[{ }^{18} \mathrm{~F}\right] \text { fluorodopa }}\end{array}$ & Resting & $\begin{array}{l}\mathrm{CN}, \mathrm{VS} \text { and } \mathrm{ACC}(\mathrm{PDD}<\mathrm{PD}-\mathrm{NC}, \mathrm{HC}) \\
\downarrow \mathrm{DaT} \text { in CN correlated with MMSE }\end{array}$ \\
\hline Nagano-Saito et al. (112) & PD-NC & $\begin{array}{l}\text { PET } \\
{\left[{ }^{18} \text { F]fluorodopa }\right.} \\
\text { PET FDG }\end{array}$ & Resting & $\begin{array}{l}\text { RCPM score positively correlated with the FDOPA Ki in the left } \\
\text { hippocampus and ACC }\end{array}$ \\
\hline Van Beilen et al. (113) & PD-NC & $\begin{array}{l}\text { PET } \\
{\left[{ }^{18} \mathrm{~F}\right] \text { fluorodopa }}\end{array}$ & Resting & $\begin{array}{l}\downarrow \text { FDOPA in CN correlated with executive, memory and language } \\
\text { composite scores }\end{array}$ \\
\hline Nobili et al. (114) & $\begin{array}{l}\text { PD-NC } \\
\text { ET }\end{array}$ & $\begin{array}{l}\text { SPECT } \\
{\left[{ }^{123} \text { I]FP-CIT }\right.}\end{array}$ & Resting & $\begin{array}{l}\text { Caudate and right putamen (PD-NC }<\text { ET) } \\
\downarrow D a T \text { in CN correlated with executive score deficits }\end{array}$ \\
\hline Polito et al. (115) & PD-NC & $\begin{array}{l}\text { SPECT } \\
{ }^{123} \text { I]FP-CIT } \\
\text { PET FDG }\end{array}$ & Resting & $\begin{array}{l}\downarrow D a T \text { in CN correlated with verbal fluency performance } \\
\downarrow D a T \text { in CN modulates hypometabolism in ACC and DLPFC }\end{array}$ \\
\hline Niethammer et al. (116) & PD-NC & $\begin{array}{l}\text { SPECT } \\
{\left[{ }^{123} \text { IJFP-CIT }\right.} \\
\text { PET FDG }\end{array}$ & Resting & Correlation of DAT CN uptake and PDCP expression \\
\hline Sawamoto et al. (117) & PD-NC & $\begin{array}{l}\text { PET } \\
{\left[{ }^{11} \mathrm{C}\right] \text {-raclopride PET FDG }}\end{array}$ & Resting & $\begin{array}{l}\downarrow R A C \text { binding in ACC and MPFC in PD } \\
\downarrow \text { dopamine release in CN in PD in working memory task }\end{array}$ \\
\hline Christopher et al. (118) & $\begin{array}{l}\text { PD-MCl } \\
\text { PD-NC }\end{array}$ & $\begin{array}{l}{\left[{ }^{11} \mathrm{C}\right] \text { FLB } 457 \text { PET }} \\
{\left[{ }^{11} \mathrm{C}\right] \text {-DTBZ PET }}\end{array}$ & Resting & $\begin{array}{l}\downarrow \mathrm{D} 2 \text { binding in salience network PD-MCl < PD-NC } \\
\downarrow \mathrm{D} 2 \text { binding in PHG and insula correlated with memory performance } \\
\downarrow \mathrm{D} 2 \text { binding in ACC and insula correlated with executive function }\end{array}$ \\
\hline \multicolumn{5}{|l|}{ Cholinergic imaging } \\
\hline Bohnen et al. (119) & $\begin{array}{l}\text { PDD } \\
\text { PD-NC } \\
\text { LBD }\end{array}$ & {$\left[{ }^{11} \mathrm{C}\right]-\mathrm{PMP}$ AChE } & Resting & $\downarrow$ Global cortical AChE of $12.9 \%$ in PD-NC, $19.8 \%$ in PDD $<\mathrm{HC}$ \\
\hline
\end{tabular}


TABLE 2 | Continued

\begin{tabular}{|c|c|c|c|c|}
\hline Studies & Population & $\begin{array}{l}\text { Radioligand and } \\
\text { technique }\end{array}$ & State & Main results/findings \\
\hline Hilker et al. (120) & PDD PD-NC & {$\left[{ }^{11} \mathrm{C}\right]-\mathrm{MP} 4 \mathrm{~A} A \mathrm{AChE}$} & Resting & $\begin{array}{l}\downarrow \text { Global cortical AChE of } 29.7 \% \text { in PDD and } 10.7 \% \text { in PD-NC }<\mathrm{HC} \text { ) } \\
\downarrow \text { AChE in left inferior parietal lobule, precentral gyrus, and right PCC } \\
\text { (PDD < PD-NC) }\end{array}$ \\
\hline Gilman et al. (121) & PD-NC & {$\left[{ }^{11} \mathrm{C}\right]-\mathrm{PMP}$ AChE } & Resting & $\begin{array}{l}\downarrow \text { Global cortical AChE of } 15.3 \% \text { (PD-NC }<\mathrm{HC} \text { ) } \\
\text { Regional reductions mainly located in temporal, parietal,occipital } \\
\text { cingulate cortices as well as amygdala and hippocampus. }\end{array}$ \\
\hline Klein et al. (122) & $\begin{array}{l}\text { PD-NC } \\
\text { PDD } \\
\text { LBD }\end{array}$ & $\begin{array}{l}{\left[{ }^{11} \mathrm{C}\right]-\mathrm{MP} 4 \mathrm{~A} \text { AChE }} \\
{ }^{18} \mathrm{~F} \text { Fdopa } \\
{ }^{18} \mathrm{FDG} \text { PET }\end{array}$ & Resting & $\begin{array}{l}\downarrow \text { Global cortical AChE of } 22.6 \% \text { in PD-NC, } 33.2 \% \text { in PDD }<\mathrm{HC} \\
\text { Global cortical reductions from frontal to occipital areas PDD }<\text { PD-NC } \\
\text { and } \mathrm{HC}\end{array}$ \\
\hline Kotagal et al. (123) & $\begin{array}{l}\text { PD-NC } \\
\text { PDD } \\
\text { LBD }\end{array}$ & $\left.{ }^{11} \mathrm{C}\right]-\mathrm{PMP}$ AChE & Resting & $\downarrow$ thalamic AChE of $12.8 \%$ in PD-NC, $19.8 \%<\mathrm{HC}$ \\
\hline Shimada et al. (124) & $\begin{array}{l}\text { LBD } \\
\text { AD }\end{array}$ & {$\left[{ }^{11} \mathrm{C}\right]-\mathrm{MP} 4 \mathrm{~A} A \mathrm{AChE}$} & Resting & $\begin{array}{l}\downarrow \text { Global cortical AChE of } 27.8 \% \text { (LBD }<\mathrm{AD} \text { ) } \\
\text { Regional reductions mainly located in temporal, parietal, occipital, } \\
\text { cingulate cortices (in order of reduction) }\end{array}$ \\
\hline Meyer et al. (125) & $\begin{array}{l}\text { PD-NC } \\
\text { PD-MCl }\end{array}$ & {$\left[{ }^{18} \mathrm{~F}\right]$-Fluoro-A-85380 } & Resting & $\begin{array}{l}\downarrow \text { Global cortical and subcortical } \alpha 4 \beta 2^{*} \text {-nicotinic acetylcholine receptor } \\
\text { PD-MCI }<\text { PD, } \\
\text { Regional reductions in hippocampus, amygdala, cerebellum, thalamus, } \\
\text { and putamen }\end{array}$ \\
\hline Colloby et al. (126) & $\begin{array}{l}\text { DLB } \\
A D\end{array}$ & {$[123 \mid]-5-\mid A-85380$} & Resting & $\begin{array}{l}\downarrow \text { Global cortical and subcortical nicotinic acetylcholine receptor in left } \\
\text { frontal gyri and ACC DLB }<\text { AD } \\
\downarrow \text { Global nicotinic acetylcholine receptor correlated with executive tasks. }\end{array}$ \\
\hline \multicolumn{5}{|l|}{ Protein deposition } \\
\hline \multicolumn{5}{|l|}{ A. Amyloid } \\
\hline Edison et al. (127) & $\begin{array}{l}\text { PDD } \\
\text { LBD PD-NC }\end{array}$ & {$\left[{ }^{11} \mathrm{C}\right] \mathrm{PIB}-\mathrm{PET}$} & Resting & $\begin{array}{l}\text { Amyloid positive were found in PDD (2/12) and DLB (11/13) when } \\
\text { compared to PD-NC and healthys } \\
\text { Regional amyloid deposition in associative, cingulate cortices and } \\
\text { striatum }\end{array}$ \\
\hline Jokinen et al. (128) & $\begin{array}{l}\text { PDD } \\
\text { PD-NC }\end{array}$ & $\begin{array}{l}{\left[{ }^{11} \mathrm{C}\right] \mathrm{PIB}-\mathrm{PET}} \\
\text { FDG PET }\end{array}$ & Resting & No differences in amyloid deposition \\
\hline Gomperts et al. (129) & $\begin{array}{l}\text { PD-MCl } \\
\text { PD-NC }\end{array}$ & {$\left[{ }^{11} \mathrm{C}\right] \mathrm{PIB}-\mathrm{PET}$} & Resting & $\begin{array}{l}\text { No differences in amyloid deposition in precuneus at baseline (PD-NC }= \\
\text { PD-MCl) } \\
\uparrow P \text { PB retention in precuneus at baseline predicted a greater risk of } \\
\text { conversion to PDD. }\end{array}$ \\
\hline Petrou et al. (130) & $\begin{array}{l}\text { PDD } \\
\text { PD-MCl } \\
\text { LBD PD-NC }\end{array}$ & {$\left[{ }^{11} \mathrm{C}\right] \mathrm{PIB}-\mathrm{PET}$} & $\begin{array}{l}\text { Resting } \\
\text { (meta-analysis) }\end{array}$ & $\begin{array}{l}\text { PiB-positive prevalence: } \\
\text { - DLB group: } 0.68(95 \% \mathrm{Cl}, 0.55-0.82) \\
\text { - PDD group: } 0.34 \text { (95\% Cl, 0.13-0.56) } \\
\text { - } \text { PD-MCl and PD-NC groups:0.05 (95\% Cl, -0.07-0.17) }\end{array}$ \\
\hline Shah et al. (131) & PD-NC & {$\left[{ }^{11} \mathrm{C}\right] \mathrm{PIB}-\mathrm{PET}$} & Resting & $\begin{array}{l}\uparrow \text { cortical }(37 \%) \text { and striatal }(16 \%) \text {-amyloid deposition (PD > HC) } \\
\text { Combined presence of striatal and cortical amyloid associated with } \\
\text { lower cognitive z score }\end{array}$ \\
\hline Ahktar et al. (132) & $\begin{array}{l}\text { PD-MCl } \\
\text { PD-NC }\end{array}$ & {$\left[{ }^{18} \mathrm{~F}\right]$-florbetapir } & Resting & $\begin{array}{l}\text { Amyloid-positive scans do not help for diagnosis of PD-MCl } \\
\uparrow \text { amyloid in PCC correlated with verbal memory performance } \\
\uparrow \text { amyloid in precuneus, frontal cortex and ACC correlated with naming } \\
\text { perfomace }\end{array}$ \\
\hline Fiorenzato et al. (133) & PD-NC & {$\left[{ }^{18} \mathrm{~F}\right]$ florbetaben } & Resting & $\begin{array}{l}\text { Amyloid positive } 10 / 48 \text { (21\%) in PD } \\
\text { Regional amyloid deposition in cortical and subcortical areas } \\
\text { associated with reduced MOCA and SDMT }\end{array}$ \\
\hline Melzer et al. (134) & $\begin{array}{l}\text { PD-MCl } \\
\text { PDD } \\
\text { PD-NC }\end{array}$ & {$\left[{ }^{18} \mathrm{~F}\right]$ florbetaben } & Resting & $\begin{array}{l}\text { No differences in amyloid deposition (PD-NC = PD-MCI = PDD) } \\
\text { Absence of clinical associations }\end{array}$ \\
\hline Na et al. (135) & PDD & {$\left[{ }^{18} \mathrm{~F}\right]$ florbetaben } & Resting & $\begin{array}{l}\text { Amyloid positive were found in PDD }(4 / 23) \\
\uparrow \text { amyloid correlated with executive function }\end{array}$ \\
\hline Biundo et al. (136) & $\begin{array}{l}\text { PDD } \\
\text { PD-MCl } \\
\text { LBD PD-NC }\end{array}$ & {$\left[{ }^{18} \mathrm{~F}\right]$ flutemetamol } & Resting & $\begin{array}{l}\text { Amyloid positive was } 50 \% \text { in } \mathrm{PD} \text { and } 50 \% \text { in LBD at baseline } \\
\uparrow \text { amyloid associated with reduced MOCA, MMSE, executive and } \\
\text { language scores } \\
\text { At follow-up there amyloid was associated with dementia. }\end{array}$ \\
\hline
\end{tabular}


TABLE 2 | Continued

\begin{tabular}{|c|c|c|c|c|}
\hline Studies & Population & $\begin{array}{l}\text { Radioligand and } \\
\text { technique }\end{array}$ & State & Main results/findings \\
\hline \multicolumn{5}{|l|}{ B. Tau } \\
\hline Gomperts et al. (137) & $\begin{array}{l}\text { PDD } \\
\text { LBD } \\
\text { PD-NC }\end{array}$ & $\begin{array}{l}{\left[{ }^{18} \mathrm{~F}\right] \mathrm{T} 807 \text { PET }} \\
{\left[{ }^{11} \mathrm{C}\right] \mathrm{PIB}-\mathrm{PET}}\end{array}$ & Resting & $\begin{array}{l}\uparrow \text { cortical tau in inferior temporal gyrus and precuneus (PDD, LBD > } \\
\text { PD-NC) } \\
\uparrow \text { cortical tau in inferior temporal gyrus correlated with MMSE and CDR }\end{array}$ \\
\hline Kantarci et al. (138) & $\begin{array}{l}\text { DLB } \\
A D\end{array}$ & $\begin{array}{l}{\left[{ }^{18} \mathrm{~F}\right] \text { T807 PET }} \\
{\left[{ }^{11} \mathrm{C}\right] \mathrm{PIB}-\mathrm{PET}}\end{array}$ & Resting & $\begin{array}{l}\uparrow \text { cortical tau in medial temporal cortex (AD > DLB) } \\
\uparrow \text { cortical tau in posterior temporoparietal and occipital cortices (DLB > } \\
\text { AD) }\end{array}$ \\
\hline Buongiorno et al. (139) & $\begin{array}{l}\text { PD-NC } \\
\text { PDD }\end{array}$ & {$\left[{ }^{18} \mathrm{~F}\right]-\mathrm{FDDNP}$} & $\begin{array}{l}\text { Resting } \\
\text { (longitudinal) }\end{array}$ & $\begin{array}{l}\uparrow \text { cortical tau in lateral temporal cortices in PD-NC with longitudinal } \\
\text { progression to PDD }\end{array}$ \\
\hline
\end{tabular}

Neuroinflammation

A. Microglial activation

\begin{tabular}{|c|c|c|c|c|}
\hline Edison et al. (140) & $\begin{array}{l}\text { PDD } \\
\text { PD-NC }\end{array}$ & $\begin{array}{l}{\left[{ }^{11} \mathrm{C}\right](R) P K 11195-\mathrm{PET}} \\
{\left[{ }^{11} \mathrm{C}\right] \mathrm{PIB}-\mathrm{PET}} \\
\text { FDG-PET }\end{array}$ & Resting & $\begin{array}{l}\uparrow \text { microglial activation in ACC, PCC, frontal, temporal, pariental cortices } \\
\text { and striatum (PDD > PD-NC and } \mathrm{HC} \text { ) }\end{array}$ \\
\hline Fan et al. (141) & $\begin{array}{l}\text { PDD } \\
\text { AD }\end{array}$ & $\begin{array}{l}{\left[{ }^{11} \mathrm{C}\right](R) P K 11195-\mathrm{PET}} \\
\text { FDG-PET }\end{array}$ & Resting & $\uparrow$ microglial activation correlated with MMSE in AD and PDD \\
\hline Femminela et al. (142) & $\begin{array}{l}\text { PDD } \\
\text { AD }\end{array}$ & $\begin{array}{l}{\left[{ }^{11} \mathrm{C}\right](R) P K 11195-\mathrm{PET}} \\
\text { FDG-PET }\end{array}$ & Resting & $\begin{array}{l}\uparrow \text { microglial activation in hippocampal/parahippocampal areas were } \\
\text { associated with cortical atrophy and metabolism in PDD and ADD. }\end{array}$ \\
\hline \multicolumn{5}{|c|}{ B. Astroglial activation } \\
\hline Wilson et al. (143) & PD-NC & {$\left[{ }^{11} \mathrm{C}\right]-\mathrm{BU} 99008 \mathrm{PET}$} & Resting & $\begin{array}{l}\downarrow \text { astroglial expression in posterior cortical and subcortical areas in PD } \\
\text { with moderate-advanced stages } \\
\text { Astroglial expression correlated with MOCA in moderate-advanced PD. }\end{array}$ \\
\hline
\end{tabular}

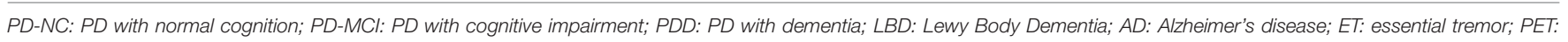

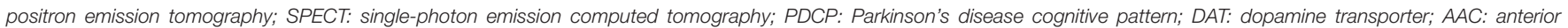

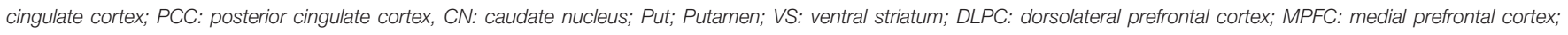

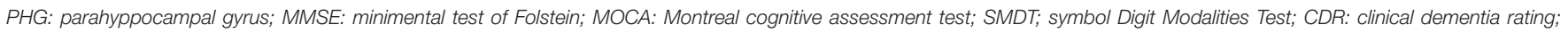
RCPM; Raven's coloured progressive matrices.

In summary, dopaminergic depletion in the caudate nucleus, as well as in the extrastriatal mesocortical and mesolimbic areas, are associated with the progression of cognitive decline in PD. Furthermore, reduced caudate dopaminergic function may be a surrogate marker of cognitive decline in PD, but first and foremost, this deficit indicates the presence of executive dysfunction.

\section{Acetylcholine Activity}

Cholinergic transmission from the basal forebrain and brainstem (nucleus basalis of Meynert and pedunculo-pontine nucleus, respectively) has been found to be reduced in PD patients (150), suggesting that it plays a relevant role in cognitive dysfunction (150).

Several radioligands that bind the vesicular acetylcholine transporter, analogues of the acetylcholinesterase, and postsynaptic nicotinic and muscarinic receptors have been assessed using SPECT and PET techniques (151).

Patients with PDD and PD-MCI show a significant cortical reduction of cholinesterase activity in the temporal, occipital, parietal, frontal, and anterior cingulate cortices $(119,121,123$, $124)$, as well as in the amygdala and thalamus $(121,123)$, compared to PD-NC patients. Interestingly, loss of cortical cholinesterase activity may also occurs in early stages of the disease in de novo PD-NC patients showing significant (12\%) losses in the medial occipital cortex (121) when compared to healthy controls. In addition, reduction of acetylcholinesterase activity in PDD patients is associated with poorer performance in global cognition (152) as well as working memory and attention deficits (151) but not with the severity of motor symptoms.

Furthermore, significant changes in post-synaptic Ach receptors have been found parallel cognitive dysfunction in PD patients (151). PD-MCI had reduced binding of nicotinic receptors in the thalamus, temporal and parietal cortices as well as hippocampus when compared to PD-NC and healthy controls, which in turn was associated with the severity of the cognitive deficit when measured with global cognitive scales (125). Importantly, post-synaptic cholinergic receptors may display compensatory increase, no change, or a decrease probably due to degeneration of non-cholinergic systems, such as noradrenergic and serotoninergic systems, to which these receptors are coupled (153) which has to be taken into account in the interpretation of the findings.

It is important to note that both dopaminergic and cholinergic dysfunction provide divergent contributions to cognitive dysfunction in PD according the "dual-syndrome" hypothesis (154). In fact, multi-radiotracer studies $(120,122)$ have showed cholinergic denervation and glucose hypometabolism is present in the neocortex from the frontal to the occipital areas in PDD patients, as well as minimal cholinergic denervation in PD-NC patients, compared to controls. On the other hand, dopaminergic denervation in the striatum, limbic, and associative cortices is 
found in both PD-NC and PDD. The relationship between cortical cholinergic loss and striatal dopaminergic denervation in PDD suggests that cognitive decline in PD appears when the disease spreads from SNc neurons to the cortex, hence the presence of cholinergic dysfunction facilitates the appearance of cognitive decline in PD.

In conclusion, cholinergic imaging in $\mathrm{PD}$ patients suffering from cognitive impairments offers an interesting approach for understanding the pathophysiological aspects of $\mathrm{PD}$, especially when used in combination with dopaminergic and glucose tracers.

\section{Protein Deposition Imaging $\beta$-Amyloid}

The development of $\beta$-amyloid specific tracers using ${ }^{11} \mathrm{C}$ Pittsburg compound $\mathrm{B}(\mathrm{PiB})$ and other radiotracers $\left({ }^{18} \mathrm{~F}\right.$ Florbetaben and ${ }^{18}$ F-Florbetapir) have provided a means for measuring in vivo amyloid pathology. To date, several studies have reported heterogeneous results in PDD and PD-MCI patients, taking into account "amyloid positivity" as AD-range of cortical amyloid deposition with PET imaging using PiB. Some studies observed the complete absence of amyloid $(127,128,134)$ while others showed mild to moderate amyloid deposition (130, 131) in PDD and PD-MCI patients compared to controls.

Importantly, due to the small sample size of the studies, a meta-analysis (130) found substantial variability of $\mathrm{PiB}$ positive results in PD patients with cognitive impairment, with higher levels of binding in patients with Lewy body dementia than in patients with PDD and PD-MCI compared to controls.

Cross-sectional and longitudinal amyloid PET studies show significant associations between cortical amyloid load and global cognitive decline as well as executive dysfunction in PDD patients $(133,135)$ with respect to PD-NC and controls. However, other studies have observed an association between memory performance with amyloid load in PDD patients (132). One longitudinal PET study (129) found that baseline amyloid binding predicted the severity of cognitive dysfunction over time in PD-NC. Furthermore, a recent prospective amyloid PET study (136) reported that cortical amyloid deposition in PDD and Lewy body dementia is associated with global cognitive deficit as well as language and attention-executive dysfunction when compared to PD-MCI and PD-NC. Interestingly, Shah et al. showed that the combination of amyloid deposition in the striatum and cortex is associated with greater cognitive impairment than amyloid deposition only in the cortex (131).

In summary, although $\beta$-amyloid deposition as measured by PET is not always observed in the brain of PDD patients, its presence may predict the presence of cognitive decline and dementia over time.

\section{Tau}

The recent development of selective and high affinity radioligands capable of binding to tau, such as ${ }^{18} \mathrm{~F}-\mathrm{AV}-1451$, has paved the way for the assessment of tau deposition in PD patients with cognitive impairment. A cross-sectional study by Gomperts et al. found that increased ${ }^{11} \mathrm{~F}-\mathrm{AV}-1451$ binding was present in the precuneus and inferior temporal gyrus only in patients with
PDD, which in turn was associated with an impairment in global cognitive scales (137).

To date, a few double tracer studies have examined the copathology between amyloid and tau in PD. The presence of tau deposition in the posterior cortical areas is in line with previous studies reporting global $\beta$-amyloid deposition in PDD patients, compared to those with PD-NC (138). In addition, a previous study found that tau binding was increased in patients with $\mathrm{A} \beta$-positive scans compared to those with $A \beta$-negative scans, suggesting that tau and $\beta$-amyloid deposition display parallel patterns of deposition. Interestingly, in this study (155) tau deposition did not differ in PD-NC, PD-MCI patients, and normal controls.

A longitudinal PD study (139) using another radiotracer $\left({ }^{18} \mathrm{~F}-\mathrm{FDDNP}\right)$ that binds both amyloid and tau, reported increased baseline lateral temporal binding in $\mathrm{PD}-\mathrm{NC}$ patients who eventually progressed to PDD, suggesting that the basal deposition of tau and amyloid is associated with poorer future cognitive function in PD.

Although, to date, only a few imaging studies have measured tau deposition in PD, their findings suggest that it is increased in PDD patients; whereas, they found tau deposition to be relatively absent in PD-MCI and PD-NC patients. In addition, cortical tau deposition is higher with concomitant $\beta$-amyloid deposits, indicating the feasibility of detecting in vivo co-pathology of protein deposition as demonstrated in post-mortem studies (17).

\section{Neuroinflammation Imaging}

Neuroinflammation has been reported to be associated with the loss of dopaminergic neurons in the SNc of PD patients (156). Microglial cells can structurally and functionally change when they are activated by the presence of diverse agents, such as oxidative stress, $\alpha$-synuclein protein aggregation, and neurodegeneration (157). It is thought that activated microglia may display a dual role, both protective and deleterious, thus enhancing the chronic neuroinflammatory process (156). However, whether the progressive neurodegeneration is associated with increased activation of microgliosis remains unclear (158). Nevertheless, post-mortem studies have observed increased microglial activation in the limbic and cortical regions of PDD patients (159). Thus, in vivo measurements of microglial activation have begun to be pursued over the last few years.

Importantly, the expression of mitochondrial translocator protein (TSPO) is known to be associated with microglial activation. In fact, first generation TSPO tracers, such as ${ }^{11} \mathrm{C}$ (R)PK11195, have revealed increased cortical binding in PDD patients predominating in the posterior cortical regions, which is associated with reduced cortical metabolism, as measured with 18F-FDG, and with low global clinical cognitive performance (140, 141). Microglial activation has also been shown to be correlated with cortical atrophy in the hippocampus and parahippocampus in PDD patients (142). Due to the non-specific binding of ${ }^{11} \mathrm{C}-(\mathrm{R}) \mathrm{PK} 11195$, new second-generation TSPO radioligands have been developed, including ${ }^{11} \mathrm{C}$-DPA713 and ${ }^{18}$ F-FEPPA. However, to date, there have been no studies using these second-generation TSPO ligands to assess cognitive decline in $\operatorname{PD}(160,161)$. 
Astrocytes are the most abundant glial cells in the brain. Similar to microglia, astrocytes change in function and number in the presence of oxidative stress, neurodegeneration, and other factors (162). However, little is known about the role of astrogliosis and the development of cognitive impairment in PD.

Imaging of glial fibrillary acidic protein (163), an astrocytic intermediate filament, with ${ }^{11} \mathrm{C}-\mathrm{BU} 990088$ (143) revealed widespread binding in the brainstem and cortex in early PDNC patients compared to controls. In the same study, patients with moderate-late stage PD were observed to have reduced astrocyte expression in the posterior cortical and subcortical areas. They also found that glial fibrillary acidic protein expression was positively associated with global cognitive scores, suggesting a neuroprotective and compensatory mechanism of astroglial activation.

Due to the small number of microglial imaging studies, as well as the lack of specificity of the radiotracers used, the possible role of microglial activation in the cognitive dysfunction associated with PD remains unknown. Similarly, the involvement of astroglial activation in PD is beginning to emerge (164). The recent development of new TSPO radioligands and astroglial tracers will allow researchers to study the role of glial cells in the cognitive decline associated with PD more effectively.

\section{NEUROIMAGING OF IMPULSE CONTROL DISORDERS IN PATIENTS WITH PARKINSON'S DISEASE}

\section{Magnetic Resonance Imaging Grey Matter}

Whole brain studies using VBM and SBA have also been undertaken in PD patients suffering from abnormal impulsivity. There is some evidence pointing towards higher cortical thickness in PD patients with ICD (PD-ICD) in the ACC, rostral pole and OFC compared to PD patients without ICD (PDnonICD) (165-167). However, other studies have shown reduced cortical thickness in PD-ICD patients in the inferior frontal gyrus and pars orbitalis $(168,169)$ or a lack of corticometric changes between PD patients with or without ICD $(170,171)$. In a prospective study (172) found a small area of increased atrophy the anterior limb of the left internal capsule adjacent to the left caudate nucleus in PD-ICD when compared to the PDnonICD, with no other significant cortical changes. Interestingly, Tessitore et al. (167) described positive correlations between cortical thickness in the ACC and OFC and ICD severity scores (see Table 3).

In summary, morphometric studies have not yet reached conclusive results in PD-ICD patients although it might be that changes in grey matter volume are associated with lack of inhibition related to ICD behaviours in PD.

\section{White Matter}

Diffusion tensor imaging (DTI) tractography studies have reported widespread WM tract damage in PD-ICD. In particular, increased radial and axial diffusivity of the genu of corpus callosum, uncinate fasciculus, parahippocampal and pedunculopontine tracts in PD-ICD patients as compared to $\mathrm{PD}$-nonICD and controls, regardless of depression and apathy severity (169, 173-175). However, a recent study found that although PD-ICD patients had increased FA in several WM tracts, the WM regions known to be involved in reward- related behaviours were preserved (173).

In summary, only few DTI studies are available in the literature, thus future diffusional imaging studies are needed in order to ascertain the role of WM integrity in ICD.

\section{Functional MRI}

Resting fMRI studies in PD-ICD patients have observed reduced or enhanced activation in regions known to support cognitive control and inhibition of inappropriate behaviours, such as the PFC, OFC, inferior frontal cortex and ACC (165, 178, 181, 203, 209). In fact, RS fMRI studies have reported both reduced $(165,171,176)$ or increased $(178,180)$ cortico-striatal FC in areas of the limbic circuit as well as others brain-wide networks including the salience, executive, and default-mode networks $(169,170,177,181,210)$. Interestingly, these studies support the idea that dopaminergic medication is able to alter limbic cortical signals to the VS, impairing the ability to change behavioural focus in response to a change in stimulus salience $(177,178,186)$.

A recent studying using a dynamic functional network connectivity approach found dynamic functional engagement of local connectivity involving the limbic circuit, which led to the inefficient modulation of emotional processing and rewardrelated decision-making (179). It is worth mentioning that there have been very few studies assessing the topological characteristics of brain networks in these patients using graph theory analysis $(171,190)$. The studies above suggest that, in PD-ICD patients, connectivity is dysfunctional within and between dopaminergic neuronal circuitries involving disrupted communications between important subcortical and limbic-cognitive cortical regions. This implies that the neural mechanisms associated with ICDs in PD patients span molecular to system levels, which are complex and dynamic, and that they cannot already draw a clear and complete picture of ICDs in PD patients.

Previous fMRI studies using reward-related tasks in PD-ICD patients have reported discrepant results. While two studies pointed towards diminished activation in the right VS, OFC and ACC $(182,184)$, three other studies reported higher activation in the VS, anterior prefrontal cortex (PFC), ACC, and OFC (183, $185,186)$. Interestingly, a recent study proposed a hypothesis for this cortico-subcortical interaction, suggesting that the right VS plays a critical role in modulating the functional dynamics of inhibitory-control in frontal regions when PD-ICD patients face penalties (187) pointing to the possibility that these nonunidirectional changes are mediated by various psychological and neural mechanisms.

Furthermore, previous studies have investigated the role of dopaminergic medications during the execution of an ICD-related task. For example, one study performed in PDICD patients with and without dopaminergic medication during a gambling task reported medication-independent and medication-related differences in neural activity, which may set a permissive stage for the emergence of ICD during dopamine replacement therapy in PD patients (188). 
TABLE 3 | Magnetic resonance imaging and radionuclide imaging studies of cognitive impairment of impulsive control disorders in Parkinson's disease.

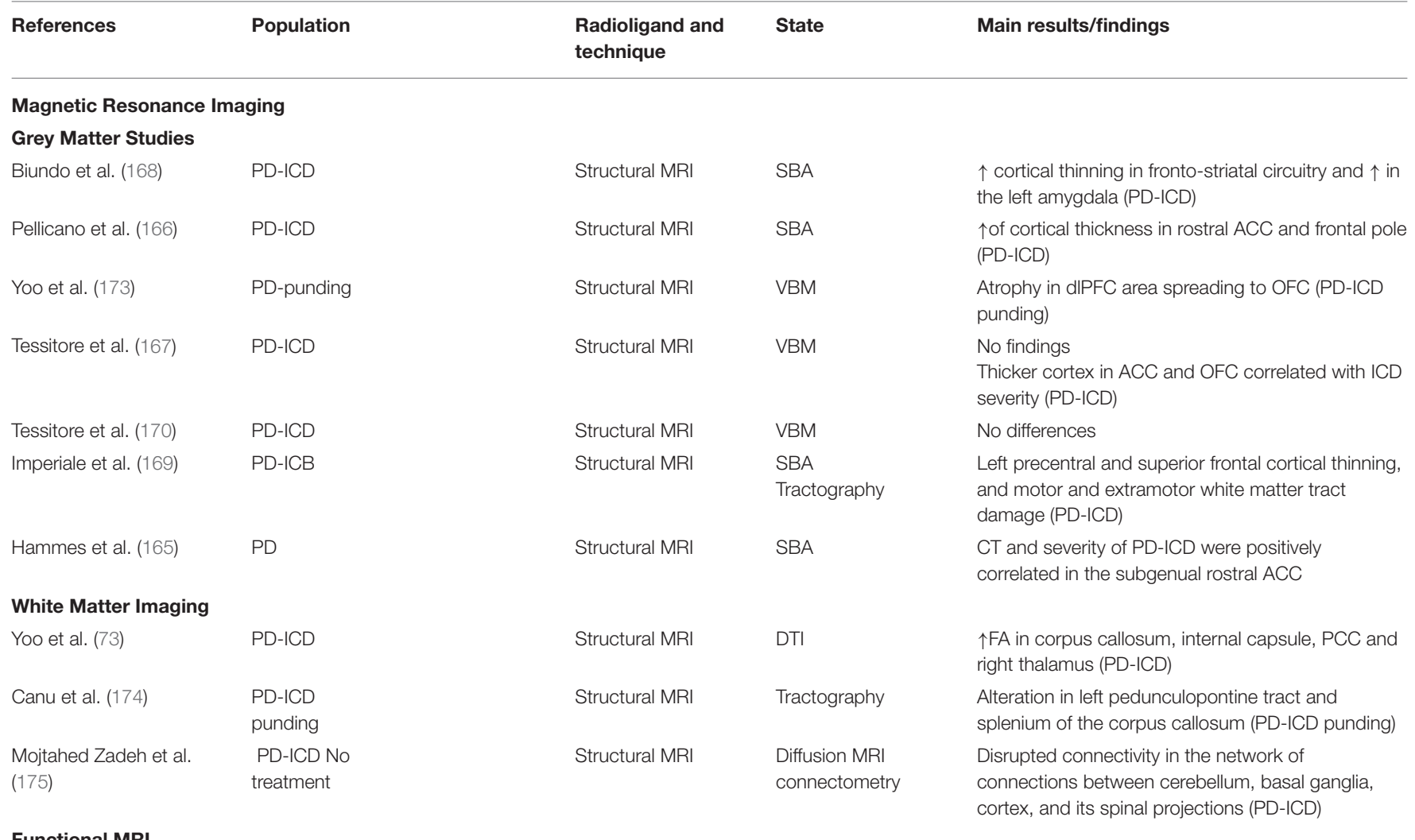

\section{Functional MRI}

a) Rs-fMRI and FC

PD-ICD

Structural MR

FC

Tessitore et al. (170) PD-ICD

Rs-fMRI

Tessitore et al. (177)

PD-ICD

Rs-fMRI

FC

Longitudinal

FC

Transversal

Ye et al. (171)

PD-ICD

Rs-fMRI

$F C+A D$

Petersen et al. (178) PD-ICD/ICB

Rs-fMRI

administration

FC

Imperiale et al. (169) PD-ICD

Rs-fMRI

FC

Rs-fMRI FC

\begin{tabular}{|c|c|}
\hline Hammes et al. (165) & PD \\
\hline $\begin{array}{l}\text { Navalpotro-Gomez et } \\
\text { al. (179) }\end{array}$ & PD-ICD \\
\hline Koh et al. (180) & $\begin{array}{l}\text { PD-high } \\
\text { impulsivity (HI) }\end{array}$ \\
\hline Mata-Marin et al. (181) & PD-HS \\
\hline
\end{tabular}

Rs-fMRI

DNFC

Rs-fMRI

Rs-fMRI

FC

FC

Functional disconnection between the left anterior Pur and left inferior temporal gyrus and the left ACC $\downarrow F C$ in DMN and central executive network and $\uparrow F C$ in salience during follow-up (PD-ICD)

$\uparrow F C$ in salience and DMN, which correlates with ICD severity (PD-ICD)

$\downarrow F C$ in frontal executive network (PD-ICD)

In somatosensory network: $\downarrow$ FC between caudate and other cortical regions

$\uparrow F C$ between VS and ACC, OFC, insula, putamen, globus pallidum (PD-ICD)

ICD severity and duration modulate FC between somatosensory, visual and cognitive networks (PD-ICD)

PD patients with more severe ICB had a $\downarrow$ FC between rostral ACC and the nucleus accumbens

Dynamic functional engagement of local connectivity involving the limbic circuit and increased local efficiency in all the aforementioned areas (ICD+) $\uparrow F C$ between the right frontoparietal network and medial visual network (PD-HI)

$\uparrow$ salience network activity with significant $\uparrow$ in the right IFG (HS+).

Functional disconnection between associative and limbic striatum with precuneus and superior parietal lobe (HS+) 
TABLE 3 | Continued

\begin{tabular}{|c|c|c|c|c|}
\hline References & Population & $\begin{array}{l}\text { Radioligand and } \\
\text { technique }\end{array}$ & State & Main results/findings \\
\hline \multicolumn{5}{|c|}{ a) fMRI during task or stimulus } \\
\hline Frosini et al. (183) & PD-PG & $\begin{array}{l}\text { fMRI with visual } \\
\text { reward }\end{array}$ & $\begin{array}{l}\text { Gambling-related } \\
\text { visual cues/ } \\
\text { neutral stimuli/rest } \\
\text { periods }\end{array}$ & $\begin{array}{l}\text { } a c t i v a t i o n \text { in bilateral ACC, medial and superior } \\
\text { frontal gyri, precuneus, right inferior parietal lobule } \\
\text { and VS (PD-ICD) }\end{array}$ \\
\hline Voon et al. (184) & $\begin{array}{l}\text { PD-ICD (PG } \\
\text { or CB) }\end{array}$ & fMRI with task & $\begin{array}{l}\text { Gambling task } \\
\text { DA administration }\end{array}$ & 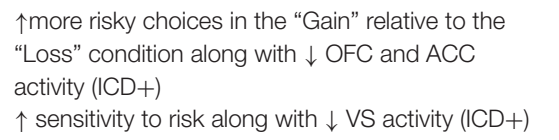 \\
\hline Politis et al. (185) & PD-HS & $\begin{array}{l}\text { fMRI with visual } \\
\text { reward }\end{array}$ & $\begin{array}{l}\text { Visual sexual cues } \\
\text { On/off }\end{array}$ & $\begin{array}{l}\text { } \text { activation in regions within limbic, paralimbic, } \\
\text { temporal, occipital, somatosensory and PFC } \\
\text { cortices and correlated with increased sexual desire } \\
\text { in VS, ACC and OFC (HS+) } \\
\text { Off: } \downarrow \text { activation during stimuli }\end{array}$ \\
\hline Girard et al. (186) & PD-HS & $\begin{array}{l}\text { fMRI with visual } \\
\text { stimuli }\end{array}$ & $\begin{array}{l}\text { Delay-discounting } \\
\text { of erotic rewards } \\
\text { On/off }\end{array}$ & $\begin{array}{l}\uparrow \text { delayed visual stimuli in on PD-HS Association } \\
\text { between VS, vmPFC and PCC }\end{array}$ \\
\hline Paz-Alonso et al. (187) & PD-ICD & fMRI during task & $\begin{array}{l}\text { lowa Gambling } \\
\text { Task }\end{array}$ & $\begin{array}{l}\uparrow \text { activation in subcortical and cortical regions } \\
\text { typically associated with reward processing and } \\
\text { inhibitory control (PD-ICD) } \\
\text { Association between ICD severity and regional } \\
\text { activations in the right insula and right IFG, } \\
\text { mediated by FC with the right VS (PD-ICD) }\end{array}$ \\
\hline Haagensen et al. (188) & PD-ICD & fMRI during task & $\begin{array}{l}\text { Seuqential } \\
\text { gambling task } \\
\text { On/off }\end{array}$ & $\begin{array}{l}\downarrow \text { "continue-to-gamble" activity in right IFG and } \\
\text { subthalamic nucleus (PD-ICD) } \\
\text { Individual risk-attitude scaled positively with } \\
\text { "continue-to-gamble" activity in right subthalamic } \\
\text { nucleus and striatum (PD-ICD) Dopaminergic } \\
\text { therapy } \downarrow \text { FC between IFG and subthalamic nucleus } \\
\text { during "continue-to-gamble" decisions and } \\
\text { attenuated striatal responses towards } \\
\text { accumulating reward }\end{array}$ \\
\hline \multicolumn{5}{|l|}{ Radionuclide imaging } \\
\hline \multicolumn{5}{|l|}{ Glucose metabolism } \\
\hline Tahmasian et al. (189) & PD-ICD & PET FDG & Resting & $\begin{array}{l}\text { Patients with } \uparrow \text { impulsivity } \uparrow \text { metabolism in OFC, } \\
\text { ACC and right insula }\end{array}$ \\
\hline Verger et al. (190) & PD-ICD & PET FDG & Resting & $\begin{array}{l}\text { Right middle and inferior temporal gyri (ICD+ >ICD) } \\
\uparrow \text { connectivity of these areas with OFC. } \\
\downarrow \text { connectivity with right parahippocampus and with } \\
\text { the left caudate (PD-ICD) }\end{array}$ \\
\hline Marin-Lahoz et al. (191) & PD-ICD & PET FDG & Resting & $\begin{array}{l}\uparrow \text { metabolism in widespread areas comprising PFC, } \\
\text { both amygdalae and default mode network hubs } \\
\text { (PD-ICD > PD-nonlCD-) } \downarrow \text { metabolism in right } \\
\text { caudate (PD-ICD }<\mathrm{HC} \text { ) }\end{array}$ \\
\hline \multicolumn{5}{|c|}{ Molecular studies focusing dopaminergic system } \\
\hline \multicolumn{5}{|c|}{ a) Dopamine transporter (DaT) or F-Dopa } \\
\hline Cilia et al. (192) & PD-PG & $\begin{array}{l}\text { SPECT } \\
{\left[{ }^{123} \mid\right] \text { FP-CIT }}\end{array}$ & Resting & $\downarrow$ VS (PD-ICD < PD-nonlCD) \\
\hline
\end{tabular}


TABLE 3 | Continued

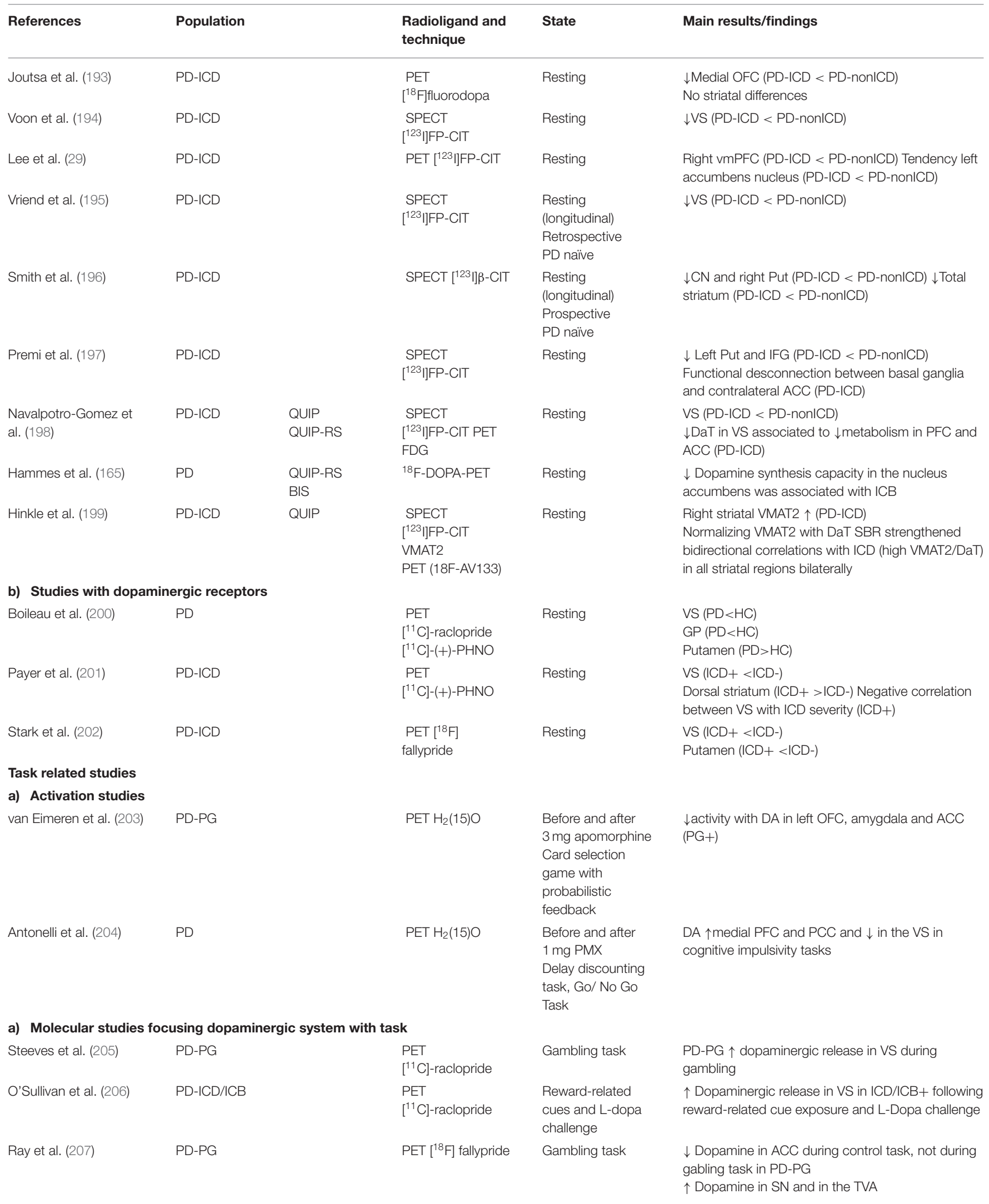


TABLE 3 | Continued

\begin{tabular}{lll}
\hline Wu et al. (208) & PD-ICD single \\
or multiple & PET & $\begin{array}{l}\text { Reward-related } \\
\text { visual cues/neutral } \uparrow \quad \text { multiple ICD patients in response to reward cues } \\
\text { visual cues }\end{array}$
\end{tabular}

PD-PG, PD patients with pathological gambling; G-SAS, Gambling Symptom Assessment Scale; BIS, Barratt Impulsiveness Scale 11; MRI, magnetic resonance imaging; VBM, voxelbased morphometry; SBA, Surface-based analysis; OFC, orbitofrontal cortex; PD-ICD, PD patients with impulse control disorder; MIDI, Minnesota impulse disorder inventory; QUIP, Questionnaire for Impulsive-Compulsive Disorders; CT, cortical thickness; ICB, impulse control behaviours; ACC, anterior cingulate cortex; IFG, inferior frontal gyrus; dIPFC, dorsolateral prefrontal cortex; TCI-R, Temperament and Character Inventory-Revised; DTI, diffusion tensor imaging; FA, fractional anisotropy; PRS, Punding Rating Scale; rs-fMRI, resting statefunctional MRI; CF, functional connectivity; DMN, default-mode network; DA, dopaminergic agonists; $P D-C B, P D$ patients with compulsive buying; VS, ventral striatum; PD-HS, PD patients with hypersexuality; MGS, Massachusetts Gambling Screen, DDS, dopaminergic dysregulation syndrome; PCC, posterior cingulate cortex; ASBPD, Ardouin Scale of Behaviour in Parkinson's disease; SPECT, single-photon emission computed tomography; PD-ICD, PD patients with impulse control disorder; OFC, orbitofrontal cortex; SOGS, South Oaks Gambling Scale; PFC, prefrontal cortex; ACC, Anterior cingulate cortex; PCC, posterior cingulate cortex; BIS, Barratt Impulsiveness Scale 11; PET, positron emission tomography;

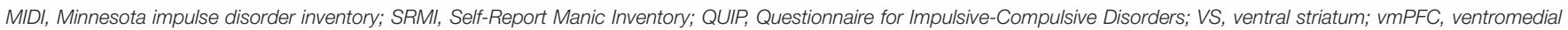

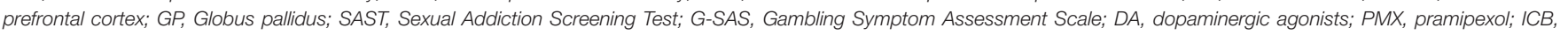
impulse control behaviors; DDS, dopaminergic dysregulation syndrome; SN, substantia nigra; VTA, ventral tegmental area.

In conclusion, altered patterns of resting FC in regions involved in cognitive control and inhibition of inappropriate behaviour are associated with ICD in PD, with an important putative effect of dopaminergic medication in the FC between areas of the limbic system and VS participating in the inhibitorycontrol in the reward circuitry.

\section{Nuclear Imaging Glucose Metabolism}

Studies with ${ }^{18}$ F-FDG PET in ICD show heterogeneous methodology, which can lead to some discrepant findings. Some of them have evidenced higher metabolic rates in the OFC, $\mathrm{AAC}$, and insula in PD patients with higher impulsivity scores (189), with increased connectivity between the parahippocampus and the caudate (190) in patients with ICD respect to nonICD. A recent systematic review stated that medicated PD-ICDs show increased metabolism in OFC and cingulate cortices, VS, amygdala, insula, temporal and supramarginal gyri (210). In the same line, a recent study suggests that brain metabolism is more preserved in PD-ICD patients than in patients without ICD, which could be related to ICD development (191). In contrast, a single study in PD-ICDs patients reported an association of lower DAT availability in the VS with lower FDG uptake in several cortical areas belonging to the limbic and associative circuits as well as in other regions involved in reward and inhibition processes (198). All these evidences can be matter of debate regarding metabolic studies in general population, which have largely demonstrated that, the hypometabolism of brain regions from "control networks" such as the PFC or the ACC could increase their vulnerability to relapse since it would interfere with cognitive inhibition.

Taken together, available data suggest that ICDs in PD patients are associated with functional alterations (with the influence of dopaminergic treatment) within the mesocorticolimbic network that could affect the control of impulse and lead to impaired inhibitory mechanisms. Although most studies show hypermetabolism in areas of mesocorticolimbic system involved with inhibition and cognitive control networks, one study looking at the relationship of cerebral metabolism and dopaminergic denervation found hypometabolic limbic and associative areas which in turn correlated with the severity of dopaminergic degeneration in the ventral striatum.

\section{Dopamine}

The most severe dopaminergic cell loss in PD patients occurs in the ventrolateral $\mathrm{SNc}$, leading to dopaminergic deficits mostly in the posterior putamen, ultimately affecting the function of the motor circuit of the basal ganglia (211). However, molecular neuroimaging studies in PD-ICD patients, have revealed that patients also have decreased dopaminergic innervation in the ventral striatum (VS), as measured by DAT SPECT and PET (165, 192, 196-199, 212, 213). Nevertheless, not all studies reported previous finding (193). Moreover, reduced mesolimbic DAT availability has been reported even before the emergence of ICDs, indicating that it may be a predisposing factor for the development of these disorders $(195,196)$ once dopaminergic treatment is initiated.

Interpretation of altered DAT binding can sometimes be confusing because of two reasons. First, DAT availability may not correlate with dopaminergic neuron counts in PD patients (214). Second, its variation can reflect a functional downregulation in order to increase available dopamine in the synapse, given that the striatal dopamine synthesis capacity in PD-ICDs patients is not reduced, compared to matched PD-nonICDs (215).

On the other hand, functional molecular studies indicate that PD-ICDs patients have a higher release of dopamine in the VS during reward-related tasks (205, 206, 208). Moreover, there is also some evidence of a negative association between the VS dopamine synthesis capacity and ICD severity. Importantly, dopaminergic changes can be also measured outside the striatum. In fact, extrastriatal D2/D3 dopamine receptors can be measured using high-affinity radiotracers (such as [18F] fallypride or [11C] FLB-457). For example, one study in PD patients with pathological gambling showed a reduction in [11C] FLB-457 binding potential in the midbrain during gambling, where D2/D3 receptors are dominated by autoreceptors, along with low dopaminergic tone in the anterior cingulate cortex (ACC) (216).

Taken together, mounting evidence suggests that abnormal dopaminergic innervation or tone in the VS and possibly in the mesocortical circuit are key factors in the development of ICD in PD patients, and could potentially be used in the future as biomarkers for identifying patients at risk of developing 
such abnormal behaviour when exposed to dopaminergic agents, especially DA.

\section{CONCLUSION}

In the current review, we highlighted the available and emerging MRI and radionuclide imaging (PET and SPECT studies) techniques used to assess cognitive impairment and ICD in PD. Although several limitations of the aforementioned studies are worth mentioning, including the literature review is not systematic, sample sizes are limited in some studies and different experimental designs and analysis techniques have been used, their findings still shed light on the potential usefulness of imaging for early diagnosing and monitoring the cognitive and neuropsychiatric symptoms of PD. Nevertheless, multimodal multimodal functional and structural longitudinal studies in early PD patients in large well-defined cohorts using

\section{REFERENCES}

1. Gibb WRG, Lees AJ. Anatomy, pigmentation, ventral and dorsal subpopulations of the substantia nigra, and differential cell death in Parkinson's disease. J Neurol Neurosurg Psychiatry. (1991) 54:38896. doi: 10.1136/jnnp.54.5.388

2. Mann DMA, Yates PO. Possible role of neuromelanin in the pathogenesis of Parkinson's disease. Mech Ageing Dev. (1983) 21:193-203. doi: 10.1016/0047-6374(83)90074-X

3. Aarsland D, Andersen K, Larsen JP, Lolk A, Kragh-Sørensen P. Prevalence and characteristics of dementia in Parkinson disease: an 8-year prospective study. Arch Neurol. (2003) 60:387-92. doi: 10.1001/archneur.60.3.387

4. Williams-Gray CH, Mason SL, Evans JR, Foltynie T, Brayne C, Robbins TW, et al. The CamPaIGN study of Parkinson's disease: 10-year outlook in an incident population-based cohort. J Neurol Neurosurg Psychiatry. (2013) 84:1258-64. doi: 10.1136/jnnp-2013-305277

5. Hely MA, Reid WGJ, Adena MA, Halliday GM, Morris JGL. The Sydney multicenter study of Parkinson's disease: the inevitability of dementia at 20 years. Move Disord. (2008) 23:837-44. doi: 10.1002/mds.21956

6. Broeders M, De Bie RMA, Velseboer DC, Speelman JD, Muslimovic D, Schmand B. Evolution of mild cognitive impairment in Parkinson disease. Neurology. (2013) 81:346-52. doi: 10.1212/WNL.0b013e3182 $9 \mathrm{c} 5 \mathrm{c} 86$

7. Gasca-Salas C, Estanga A, Clavero P, Aguilar-Palacio I, González-Redondo R, Obeso JA, et al. Longitudinal assessment of the pattern of cognitive decline in non-demented patients with advanced Parkinson's disease. J Parkinsons Dis. (2014) 4:677-86. doi: 10.3233/JPD-140398

8. Janvin CC, Larsen JP, Aarsland D, Hugdahl K. Subtypes of mild cognitive impairment in Parkinson's disease: progression to dementia. Move Disord. (2006) 21:1343-9. doi: 10.1002/mds.20974

9. Litvan I, Aarsland D, Adler CH, Goldman JG, Kulisevsky J, Mollenhauer B, et al. MDS task force on mild cognitive impairment in Parkinson's disease: critical review of PD-MCI. Move Disord. (2011) 26:181424. doi: $10.1002 / \mathrm{mds} .23823$

10. Pigott K, Rick J, Xie SX, Hurtig H, Chen-Plotkin A, Duda JE, et al. Longitudinal study of normal cognition in Parkinson disease. Neurology. (2015) 85:1276-82. doi: 10.1212/WNL.0000000000002001

11. Pedersen KF, Larsen JP, Tysnes OB, Alves G. Prognosis of mild cognitive impairment in early Parkinson disease: the Norwegian ParkWest study. JAMA Neurol. (2013) 70:580-6. doi: 10.1001/jamaneurol.2013.2110

12. Hughes TA, Ross HF, Musa S, Bhattacherjee $S$, Nathan RN, Mindham RHS, et al. A 10-year study of the incidence of and factors predicting dementia in Parkinson's disease. Neurology. (2000) 54:1596-602. doi: 10.1212/WNL.54.8.1596 advanced method of analysis are still needed in order to better predict the risk of dementia and ICD in PD patients, better understanding of pathophysiology as well as develop novel therapeutic interventions to improve patient care.

\section{DATA AVAILABILITY STATEMENT}

The original contributions presented in the study are included in the article/supplementary material, further inquiries can be directed to the corresponding author/s.

\section{AUTHOR CONTRIBUTIONS}

AM-B, MD-A, and IN-G: wrote up the original manuscript. MR-O: conception, supervision of the study, and reviewed the final manuscript. All authors contributed to the article and approved the submitted version.
13. Rinne JO, Mlic JR, Paljärvi L, Rinne UK. Dementia in Parkinson's disease is related to neuronal loss in the medial substantia nigra. Ann Neurol. (1989) 26:47-50. doi: 10.1002/ana.410260107

14. Del Tredici K, Braak H. Dysfunction of the locus coeruleus-norepinephrine system and related circuitry in Parkinson's disease-related dementia. J Neurol Neurosurg Psychiatry. (2013) 84:774-83. doi: 10.1136/jnnp-2011-301817

15. Halliday GM, Blumbergs PC, Cotton RGH, Blessing WW, Geffen LB. Loss of brainstem serotonin- and substance P-containing neurons in Parkinson's disease. Brain Res. (1990) 510:104-7. doi: 10.1016/0006-8993(90)9 0733-R

16. Tagliavini F, Pilleri G, Bouras C, Constantinidis J. The basal nucleus of Meynert in idiopathic Parkinson's disease. Acta Neurol Scand. (1984) 70:208. doi: 10.1111/j.1600-0404.1984.tb00798.x

17. Compta Y, Parkkinen L, O'Sullivan SS, Vandrovcova J, Holton JL, Collins C, et al. Lewy- and Alzheimer-type pathologies in Parkinson's disease dementia: which is more important? Brain. (2011) 134:1493505. doi: 10.1093/brain/awr031

18. Aarsland D, Marsh L, Schrag A. Neuropsychiatric symptoms in Parkinson's disease. Move Disord. (2009) 24:2175-86. doi: 10.1002/mds.22589

19. Weintraub D, Koester J, Potenza MN, Siderowf AD, Stacy M, Voon V, et al. Impulse control disorders in Parkinson disease: a cross-sectional study of 3090 patients. Arch Neurol. (2010) 67:589-95. doi: 10.1001/archneurol.2010.65

20. Bastiaens J, Dorfman BJ, Christos PJ, Nirenberg MJ. Prospective cohort study of impulse control disorders in Parkinson's disease. Move Disord. (2013) 28:327-33. doi: 10.1002/mds.25291

21. Samuel M, Rodriguez-Oroz M, Antonini A, Brotchie JM, Ray Chaudhuri K, Brown RG, et al. Management of impulse control disorders in Parkinson's disease: controversies and future approaches. Move Disord. (2015) 30:1509. doi: 10.1002/mds.26099

22. Hutton C, Draganski B, Ashburner J, Weiskopf N. A comparison between voxel-based cortical thickness and voxel-based morphometry in normal aging. NeuroImage. (2009) 48:371-80. doi: 10.1016/j.neuroimage.2009. 06.043

23. Camicioli R, Mooler M, Kinney A, Corbridge E, Glassberg K, Kaye J. Parkinson's disease is associated with hippocampal atrophy. Mov Disord. (2003) 18:784-90. doi: 10.1002/mds.10444

24. Brück A, Kurki T, Kaasinen V, Vahlberg T, Rinne JO. Hippocampal and prefrontal atrophy in patients with early non-demented Parkinson's disease is related to cognitive impairment. J Neurol Neurosurg Psychiatry. (2004) 75:1467-9. doi: 10.1136/jnnp.2003.031237

25. Song SK, Lee JE, Park HJ, Sohn YH, Lee JD, Lee PH. The pattern of cortical atrophy in patients with Parkinson's disease according to cognitive status. Move Disord. (2011) 26:289-96. doi: 10.1002/mds.23477 
26. Choi SH, Jung TM, Lee JE, Lee SK, Sohn YH, Lee PH. Volumetric analysis of the substantia innominata in patients with Parkinson's disease according to cognitive status. Neurobiol Aging. (2012) 33:126572. doi: 10.1007/978-1-4614-1788-0

27. Beyer MK, Bronnick KS, Hwang KS, Bergsland N, Tysnes OB, Larsen JP, et al. Verbal memory is associated with structural hippocampal changes in newly diagnosed Parkinson's disease. J Neurol Neurosurg Psychiatry. (2013) 84:23-8. doi: 10.1136/jnnp-2012-303054

28. Pagonabarraga J, Corcuera-Solano I, Vives-Gilabert Y, Llebaria G, GarcíaSánchez C, Pascual-Sedano B, et al. Pattern of regional cortical thinning associated with cognitive deterioration in Parkinson's disease. PLoS ONE. (2013) 8:e54980. doi: 10.1371/journal.pone.0054980

29. Lee JE, Cho KH, Song SK, Kim HJ, Lee HS, Sohn YH, et al. Exploratory analysis of neuropsychological and neuroanatomical correlates of progressive mild cognitive impairment in Parkinson's disease. J Neurol Neurosurg Psychiatry. (2014) 85:7-16. doi: 10.1136/jnnp-2013-305062

30. Filoteo JV, Reed JD, Litvan I, Harrington DL. Volumetric correlates of cognitive functioning in nondemented patients with Parkinson's disease. Move Disord. (2014) 29:360-7. doi: 10.1002/mds.25633

31. Kandiah N, Zainal NH, Narasimhalu K, Chander RJ, Ng A, Mak E, et al. Hippocampal volume and white matter disease in the prediction of dementia in Parkinson's disease. Parkinsonism Relat Disord. (2014) 20:12038. doi: 10.1016/j.parkreldis.2014.08.024

32. Wen MC, Ng A, Chander RJ, Au WL, Tan LCS, Kandiah N. Longitudinal brain volumetric changes and their predictive effects on cognition among cognitively asymptomatic patients with Parkinson's disease. Parkinsonism Relat Disord. (2015) 21:483-8. doi: 10.1016/j.parkreldis.2015.02.014

33. Foo H, Mak E, Chander RJ, $\mathrm{Ng} \mathrm{A,} \mathrm{Au} \mathrm{WL,} \mathrm{Sitoh} \mathrm{YY,} \mathrm{et} \mathrm{al.}$ Associations of hippocampal subfields in the progression of cognitive decline related to Parkinson's disease. NeuroImage Clin. (2016) 14:3742. doi: 10.1016/j.nicl.2016.12.008

34. Low A, Foo H, Yong TT, Tan LCS, Kandiah N. Hippocampal subfield atrophy of CA1 and subicular structures predict progression to dementia in idiopathic Parkinson's disease. J Neurol Neurosurg Psychiatry. (2019) 90:681-7. doi: 10.1136/jnnp-2018-319592

35. Zheng D, Chen C, Song WC, Yi ZQ, Zhao PW, Zhong JG, et al. Regional gray matter reductions associated with mild cognitive impairment in Parkinson's disease: a meta-analysis of voxel-based morphometry studies. Behav Brain Res. (2019) 371:111973. doi: 10.1016/j.bbr.2019.111973

36. Gasca-Salas C, García-Lorenzo D, Garcia-Garcia D, Clavero P, Obeso JA, Lehericy S, et al. Parkinson's disease with mild cognitive impairment: severe cortical thinning antedates dementia. Brain Imaging Behav. (2019) 13:1808. doi: 10.1007/s11682-017-9751-6

37. Chung SJ, Yoo HS, Lee YH, Lee HS, Ye BS, Sohn YH, et al. Frontal atrophy as a marker for dementia conversion in Parkinson's disease with mild cognitive impairment. Hum Brain Mapp. (2019) 40:3784-94. doi: 10.1002/hbm.24631

38. Xu R, Hu X, Jiang X, Zhang Y, Wang J, Zeng X. Longitudinal volume changes of hippocampal subfields and cognitive decline in Parkinson's disease. Quant Imaging Med Surg. (2020) 10:220-32. doi: 10.21037/qims.2019.10.17

39. Zhou C, Guan XJ, Guo T, Zeng QL, Gao T, Huang PY, et al. Progressive brain atrophy in Parkinson's disease patients who convert to mild cognitive impairment. CNS Neurosci Ther. (2020) 26:117-25. doi: 10.1111/cns.13188

40. Donzuso G, Monastero R, Cicero CE, Luca A, Mostile G, Giuliano $\mathrm{L}$, et al. Neuroanatomical changes in early Parkinson's disease with mild cognitive impairment: a VBM study; the Parkinson's Disease Cognitive Impairment Study (PaCoS). Neurol Sci. (2021) 42:372331. doi: 10.1007/s10072-020-05034-9

41. Kamagata K, Motoi Y, Abe O, Shimoji K, Hori M, Nakanishi A, et al. White matter alteration of the cingulum in Parkinson disease with and without dementia: evaluation by diffusion tensor tract-specific analysis. Am J Neuroradiol. (2012) 33:890-5. doi: 10.3174/ajnr.A2860

42. Hattori T, Orimo S, Aoki S, Ito K, Abe O, Amano A, et al. Cognitive status correlates with white matter alteration in Parkinson's disease. Hum Brain Mapp. (2012) 33:727-39. doi: 10.1002/hbm.21245

43. Deng B, Zhang Y, Wang L, Peng K, Han L, Nie K, et al. Diffusion tensor imaging reveals white matter changes associated with cognitive status in patients with Parkinson's disease. Am J Alzheimers Dis Other Dementias. (2013) 28:154-64. doi: 10.1177/1533317512470207
44. Melzer TR, Watts R, Macaskill MR, Pitcher TL, Livingston L, Keenan RJ, et al. White matter microstructure deteriorates across cognitive stages in Parkinson disease. Neurology. (2013) 80:1841-9. doi: 10.1212/WNL.0b013e3182929f62

45. Agosta F, Canu E, Stefanova E, Sarro L, Tomić A, Špica V, et al. Mild cognitive impairment in Parkinson's disease is associated with a distributed pattern of brain white matter damage. Hum Brain Mapp. (2014) 35:19219. doi: 10.1002/hbm.22302

46. Auning E, Kjærvik VK, Selnes P, Aarsland D, Haram A, Bjørnerud A, et al. White matter integrity and cognition in Parkinson's disease: a cross-sectional study. BMJ Open. (2014) 4:e003976. doi: 10.1136/bmjopen-2013-003976

47. Chen B, Fan GG, Liu H, Wang S. Changes in anatomical and functional connectivity of Parkinson's disease patients according to cognitive status. Eur J Radiol. (2015) 84:1318-24. doi: 10.1016/j.ejrad.2015.04.014

48. Bledsoe IO, Stebbins GT, Merkitch D, Goldman JG. White matter abnormalities in the corpus callosum with cognitive impairment in Parkinson disease. Neurology. (2018) 91:E224455. doi: 10.1212/WNL.0000000000006646

49. Chondrogiorgi M, Astrakas LG, Zikou AK, Weis L, Xydis VG, Antonini A, et al. Multifocal alterations of white matter accompany the transition from normal cognition to dementia in Parkinson's disease patients. Brain Imaging Behav. (2019) 13:232-40. doi: 10.1007/s11682-018-9863-7

50. Beyer MK, Aarsland D, Greve OJ, Larsen JP. Visual rating of white matter hyperintensities in Parkinson's disease. Move Disord. (2006) 21:2239. doi: 10.1002/mds. 20704

51. Lee SJ, Kim JS, Yoo JY, Song IU, Kim BS, Jung SL, et al. Influence of white matter hyperintensities on the cognition of patients with parkinson disease. Alzheimer Dis Assoc Disord. (2010) 24:227-33. doi: 10.1097/WAD.0b013e3181d71a13

52. Joki H, Higashiyama Y, Nakae Y, Kugimoto C, Doi H, Kimura K, et al. White matter hyperintensities on MRI in dementia with Lewy bodies, Parkinson's disease with dementia, Alzheimer's disease. J Neurol Sci. (2018) 385:99104. doi: 10.1016/j.jns.2017.12.018

53. Huang X, Wen MC, Ng SYE, Hartono S, Chia NSY, Choi X, et al. Periventricular white matter hyperintensity burden and cognitive impairment in early Parkinson's disease. Eur J Neurol. (2020) 27:95966. doi: 10.1111/ene.14192

54. Lewis SJG, Dove A, Robbins TW, Barker RA, Owen AM. Cognitive impairments in early Parkinson's disease are accompanied by reductions in activity in frontostriatal neural circuitry. J Neurosci. (2003) 23:63516. doi: 10.1523/JNEUROSCI.23-15-06351.2003

55. Monchi O, Petrides M, Mejia-Constain B, Strafella AP. Cortical activity in Parkinson's disease during executive processing depends on striatal involvement. Brain. (2007) 130:233-44. doi: 10.1093/brain/awl326

56. Seibert T, Murphy E, Kaestner E, Brewer J. Interregional correlations in parkinson disease and parkinson-related dementia with resting functional MR imaging. Radiology. (2012) 236:226-34. doi: 10.1148/radiol.12111280

57. Baggio HC, Sala-Llonch R, Segura B, Marti MJ, Valldeoriola F, Compta Y, et al. Functional brain networks and cognitive deficits in Parkinson's disease. Hum Brain Mapp. (2014) 35:4620-34. doi: 10.1002/hbm.22499

58. Lebedev AV, Westman E, Simmons A, Lebedeva A, Siepel FJ, Pereira JB, et al. Large-scale resting state network correlates of cognitive impairment in Parkinson's disease and related dopaminergic deficits. Front Syst Neurosci. (2014) 8:45. doi: 10.3389/fnsys.2014.00045

59. Amboni M, Tessitore A, Esposito F, Santangelo G, Picillo M, Vitale C, et al. Resting-state functional connectivity associated with mild cognitive impairment in Parkinson's disease. J Neurol. (2015) 262:42534. doi: 10.1007/s00415-014-7591-5

60. Baggio HC, Segura B, Sala-Llonch R, Marti MJ, Valldeoriola F, Compta Y, et al. Cognitive impairment and resting-state network connectivity in Parkinson's disease. Hum Brain Mapp. (2015) 36:199-212. doi: 10.1002/hbm.22622

61. Gorges M, Müller HP, Lulé D, Pinkhardt EH, Ludolph AC, Kassubek J. To rise and to fall: functional connectivity in cognitively normal and cognitively impaired patients with Parkinson's disease. Neurobiol Aging. (2015) 36:172735. doi: 10.1016/j.neurobiolaging.2014.12.026

62. Shin NY, Shin YS, Lee PH, Yoon U, Han S, Kim DJ, et al. Different functional and microstructural changes depending on duration of mild 
cognitive impairment in Parkinson disease. Am J Neuroradiol. (2016) 37:897-903. doi: 10.3174/ajnr.A4626

63. Chen B, Wang S, Sun W, Shang X, Liu H, Liu G, et al. Functional and structural changes in gray matter of parkinson's disease patients with mild cognitive impairment. Eur J Radiol. (2017) 93:16-23. doi: 10.1016/j.ejrad.2017.05.018

64. Bezdicek O, Ballarini T, RuŽička F, Roth J, Mueller K, Jech $\mathrm{R}$, et al. Mild cognitive impairment disrupts attention network connectivity in Parkinson's disease: a combined multimodal MRI and meta-analytical study. Neuropsychologia. (2018) 112:105-15. doi: 10.1016/j.neuropsychologia.2018.03.011

65. Díez-Cirarda M, Strafella AP, Kim J, Peña J, Ojeda N, Cabrera-Zubizarreta A, et al. Dynamic functional connectivity in Parkinson's disease patients with mild cognitive impairment and normal cognition. NeuroImage Clin. (2018) 17:847-55. doi: 10.1016/j.nicl.2017.12.013

66. Hou Y, Yang J, Luo C, Ou R, Zou Y, Song W, et al. Resting-state network connectivity in cognitively unimpaired drug-naïve patients with rigidity-dominant Parkinson's disease. J Neurol Sci. (2018) 395:14752. doi: $10.1016 /$ j.jns.2018.10.003

67. Wolters AF, van de Weijer SCF, Leentjens AFG, Duits AA, Jacobs HIL, Kuijf ML. Resting-state fMRI in Parkinson's disease patients with cognitive impairment: a meta-analysis. Parkinsonism Relat Disord. (2019) 62:1627. doi: 10.1016/j.parkreldis.2018.12.016

68. Fathy YY, Hepp DH, de Jong FJ, Geurts JJG, Foncke EMJ, Berendse HW, et al. Anterior insular network disconnection and cognitive impairment in Parkinson's disease. NeuroImage Clin. (2020) 28:102364. doi: 10.1016/j.nicl.2020.102364

69. Pan C, Ren J, Li L, Li Y, Xu J, Xue C, et al. Differential functional connectivity of insular subdivisions in de novo Parkinson's disease with mild cognitive impairment. Brain Imaging Behav. (2021). doi: 10.1007/s11682-021-00471-2. [Epub ahead of print].

70. Delgado-Alvarado M, Gago B, Navalpotro-Gomez I, JiménezUrbieta H, Rodriguez-Oroz MC. Biomarkers for dementia and mild cognitive impairment in Parkinson's disease. Move Disord. (2016) 31:861-81. doi: $10.1002 / \mathrm{mds} .26662$

71. Sarasso E, Agosta F, Piramide N, Filippi M. Progression of grey and white matter brain damage in Parkinson's disease: a critical review of structural MRI literature. J Neurol. (2020) 268:3144-79. doi: 10.1007/s00415-020-09863-8

72. Wu L, Liu FT, Ge JJ, Zhao J, Tang YL, Yu WB, et al. Clinical characteristics of cognitive impairment in patients with Parkinson's disease and its related pattern in 18F-FDG PET imaging. Hum Brain Mapp. (2018) 39:465262. doi: 10.1002/hbm.24311

73. Yoo HS, Yun HJ, Chung SJ, Sunwoo MK, Lee JM, Sohn YH, et al. Patterns of neuropsychological profile cortical thinning in Parkinson's disease with punding. PLoS ONE. (2015)10:e0134468. doi: 10.1371/journal.pone.0134468

74. Na Young S, Bang M, Yoo S-W, Kim JS, Yun E, Yoon U, et al. Cortical thickness from MRI to predict conversion from mild cognitive impairment to dementia in Parkinson disease: a machine learning-based model. Radiology. (2021) 300:390-9. doi: 10.1148/radiol.2021203383

75. Smith C, Malek N, Grosset K, Cullen B, Gentleman S, Grosset DG. Neuropathology of dementia in patients with Parkinson's disease: a systematic review of autopsy studies. J Neurol Neurosurg Psychiatry. (2019) 90:1234-43. doi: 10.1136/jnnp-2019-321111

76. Morales DA, Vives-Gilabert Y, Gómez-Ansón B, Bengoetxea E, Larrañaga P, Bielza C, et al. Predicting dementia development in Parkinson's disease using Bayesian network classifiers. Psychiatry Res Neuroimaging. (2013) 213:92-8. doi: 10.1016/j.pscychresns.2012.06.001

77. Leocadi M, Canu E, Donzuso G, Stojkovic T, Basaia S, Kresojević $\mathrm{N}$, et al. Longitudinal clinical, cognitive, and neuroanatomical changes over 5 years in GBA-positive Parkinson's disease patients. J Neurol. (2021). doi: 10.1007/s00415-021-10713-4. [Epub ahead of print].

78. Sampedro F, Marín-Lahoz J, Martínez-Horta S, Pagonabarraga J, Kulisevsky J. Reduced gray matter volume in cognitively preserved COMT $158 \mathrm{Val} / \mathrm{Val}$ Parkinson's disease patients and its association with cognitive decline. Brain Imaging Behav. (2020) 14:321-8. doi: 10.1007/s11682-018$0022-y$

79. Sampedro F, Marín-Lahoz J, Martínez-Horta S, Pagonabarraga J, Kulisevsky J. Early gray matter volume loss in MAPT H1H1 de Novo PD patients: a possible association with cognitive decline. Front Neurol. (2018) 9:394. doi: 10.3389/fneur.2018.00394

80. Gorges M, Müller HP, Liepelt-Scarfone I, Storch A, Dodel $\mathrm{R}$, Hilker-Roggendorf $\mathrm{R}$, et al. Structural brain signature of cognitive decline in Parkinson's disease: DTI-based evidence from the LANDSCAPE study. Ther Adv Neurol Disord. (2019) 12:1756286419843447. doi: 10.1177/1756286419843447

81. Minett T, Su L, Mak E, Williams G, Firbank M, Lawson RA, et al. Longitudinal diffusion tensor imaging changes in early Parkinson's disease: ICICLE-PD study. J Neurol. (2018) 265:1528-39. doi: 10.1007/s00415-018-8873-0

82. Agosta F, Kostic VS, Davidovic K, Kresojević N, Sarro L, Svetel M, et al. White matter abnormalities in Parkinson's disease patients with glucocerebrosidase gene mutations. Move Disord. (2013) 28:772-8. doi: 10.1002/mds.25397

83. Kamagata K, Motoi Y, Tomiyama H, Abe O, Ito K, Shimoji $\mathrm{K}$, et al. Relationship between cognitive impairment and whitematter alteration in Parkinson's disease with dementia: tract-based spatial statistics and tract-specific analysis. Eur Radiol. (2013) 23:1946-55. doi: 10.1007/s00330-013-2775-4

84. Duncan GW, Firbank MJ, Yarnall AJ, Khoo TK, Brooks DJ, Barker RA, et al. Gray and white matter imaging: a biomarker for cognitive impairment in early Parkinson's disease? Move Disord. (2016) 31:10310. doi: $10.1002 / \mathrm{mds} .26312$

85. Dalaker TO, Larsen JP, Bergsland N, Beyer MK, Alves G, Dwyer MG, et al. Brain atrophy and white matter hyperintensities in early Parkinson's disease. Move Disord. (2009) 24:2233-41. doi: 10.1002/mds.22754

86. González-Redondo R, Toledo J, Clavero P, Lamet I, García-García D, García-Eulate R, et al. The impact of silent vascular brain burden in cognitive impairment in Parkinson's disease. Eur J Neurol. (2012) 19:11007. doi: $10.1111 / \mathrm{j} .1468-1331.2012 .03682 . \mathrm{x}$

87. Raichle ME. The brain's default mode network. Ann Rev Neurosci. (2015) 38:433-47. doi: 10.1146/annurev-neuro-071013-014030

88. Tessitore A, Esposito F, Vitale C, Santangelo G, Amboni M, Russo A, et al. Default-mode network connectivity in cognitively unimpaired patients with Parkinson disease. Neurology. (2012) 79:2226-32. doi: 10.1212/WNL.0b013e31827689d6

89. Chen $\mathrm{X}$, Liu $\mathrm{M}, \mathrm{Wu} \mathrm{Z}$, Cheng $\mathrm{H}$. Topological abnormalities of functional brain network in early-stage Parkinson's disease patients with mild cognitive impairment. Front Neurosci. (2020) 14:1298. doi: 10.3389/fnins.2020.616872

90. Hou Y, Yuan X, Wei Q, Ou R, Yang J, Gong Q, et al. Primary disruption of the default mode network subsystems in drug-naïve Parkinson's disease with mild cognitive impairments. Neuroradiology. (2020) 62:68592. doi: 10.1007/s00234-020-02378-z

91. Guo W, Jin W, Li N, Gao J, Wang J, Chang Y, et al. Brain activity alterations in patients with Parkinson's disease with cognitive impairment based on resting-state functional MRI. Neurosci Lett. (2021) 747:135672. doi: 10.1016/j.neulet.2021.135672

92. Zarifkar P, Kim J, La C, Zhang K, YorkWilliams S, Levine TF, et al. Cognitive impairment in Parkinson's disease is associated with Default Mode Network subsystem connectivity and cerebrospinal fluid A $\beta$. Parkinsonism Relat Disord. (2021) 83:71-8. doi: 10.1016/j.parkreldis.2021.01.002

93. Disbrow EA, Carmichael O, He J, Lanni KE, Dressler EM, Zhang L, et al. Resting state functional connectivity is associated with cognitive dysfunction in non-demented people with Parkinson's disease. J Parkinsons Dis. (2014) 4:453-65. doi: 10.3233/JPD-130341

94. Peraza LR, Nesbitt D, Lawson RA, Duncan GW, Yarnall AJ, Khoo TK, et al. Intra- and inter-network functional alterations in Parkinson's disease with mild cognitive impairment. Hum Brain Mapp. (2017) 38:170215. doi: 10.1002/hbm.23499

95. Caminiti SP, Siri C, Guidi L, Antonini A, Perani D. The neural correlates of spatial and object working memory in elderly and Parkinson's disease subjects. Behav Neurol. (2015) 2015:10. doi: 10.1155/2015/123636

96. Giehl K, Tahmasian M, Eickhoff SB, van Eimeren T. Imaging executive functions in Parkinson's disease: an activation likelihood estimation meta-analysis. Parkinsonism Relat Disord. (2019) 63:137-42. doi: 10.1016/j.parkreldis.2019.02.015

97. Poston KL, Yorkwilliams S, Zhang K, Cai W, Everling D, Tayim FM, et al. Compensatory neural mechanisms in cognitively unimpaired Parkinson disease. Ann Neurol. (2016) 79:448-63. doi: 10.1002/ana.24585 
98. Pagonabarraga J, Kulisevsky J. Cognitive impairment and dementia in Parkinson's disease. Neurobiol Dis. (2012) 46:5906. doi: 10.1016/j.nbd.2012.03.029

99. Lucas-Jiménez O, Díez-Cirard $\mathrm{M}$, Ojeda $\mathrm{N}$, Peña J, CabreraZubizarreta A, Ibarretxe-Bilbao N. Verbal memory in Parkinson's Disease: a combined DTI and fMRI study. J Parkinsons Dis. (2015) 5:793-804. doi: 10.3233/JPD-150623

100. Bohnen NI, Koeppe RA, Minoshima S, Giordani B, Albin RL, Frey KA, et al. Cerebral glucose metabolic features of Parkinson disease and incident dementia: longitudinal study. J Nucl Med. (2011) 52:84855. doi: 10.2967/jnumed.111.089946

101. Garcia-Garcia D, Clavero P, Salas CG, Lamet I, Arbizu J, Gonzalez-Redondo $\mathrm{R}$, et al. Posterior parietooccipital hypometabolism may differentiate mild cognitive impairment from dementia in Parkinson's disease. Eur J Nucl Med Mol Imaging. (2012) 39:1767-77. doi: 10.1007/s00259-012-2198-5

102. Hosokai Y, Nishio Y, Hirayama K, Takeda A, Ishioka T, Sawada Y, et al. Distinct patterns of regional cerebral glucose metabolism in Parkinson's disease with and without mild cognitive impairment. Move Disord. (2009) 24:854-62. doi: 10.1002/mds.22444

103. Huang C, Mattis P, Perrine K, Brown N, Dhawan V, Eidelberg D. Metabolic abnormalities associated with mild cognitive impairment in Parkinson disease. Neurology. (2008) 70:14707. doi: $10.1212 / 01 . w n l .0000304050 .05332 .9 \mathrm{c}$

104. Pappatá S, Santangelo G, Aarsland D, Vicidomini C, Longo K, Bronnick $\mathrm{K}$, et al. Mild cognitive impairment in drug-naive patients with $\mathrm{PD}$ is associated with cerebral hypometabolism. Neurology. (2011) 77:135762. doi: 10.1212/WNL.0b013e3182315259

105. González-Redondo R, García-García D, Clavero P, Gasca-Salas C, GarcíaEulate R, García-Eulate R, et al. Grey matter hypometabolism and atrophy in Parkinson's disease with cognitive impairment: a two-step process. Brain. (2014) 137:2356-67. doi: 10.1093/brain/awu159

106. Huang C, Mattis P, Tang C, Perrine K, Carbon M, Eidelberg D, et al. Metabolic brain networks associated with cognitive function in Parkinson's disease. NeuroImage. (2007) 34:71423. doi: 10.1016/j.neuroimage.2006.09.003

107. Tard C, Demailly F, Delval A, Semah F, Defebvre L, Dujardin K, et al. Hypometabolism in posterior and temporal areas of the brain is associated with cognitive decline in Parkinson's disease. J Parkinsons Dis. (2015) 5:56974. doi: 10.3233/JPD-150583

108. Baba T, Hosokai Y, Nishio Y, Kikuchi A, Hirayama K, Suzuki K, et al. Longitudinal study of cognitive and cerebral metabolic changes in Parkinson's disease. J Neurol Sci. (2017) 15:288-93. doi: 10.1016/j.jns.2016.11.068

109. Rinne JO, Portin R, Ruottinen H, Nurmi E, Bergman J, Haaparanta M, et al. Cognitive impairment and the brain dopaminergic system in Parkinson disease. Arch Neurol. (2000) 57:470-5. doi: 10.1001/archneur.57.4.470

110. Walker Z, Costa DC, Walker RWH, Shaw K, Gacinovic S, Stevens T, et al. Differentiation of dementia with Lewy bodies from Alzheimer's disease using a dopaminergic presynaptic ligand. J Neurol Neurosurg Psychiatry. (2002) 73:134-40. doi: 10.1136/jnnp.73.2.134

111. Ito K, Nagano-Saito A, Kato T, Arahata Y, Nakamura A, Kawasumi Y, et al. Striatal and extrastriatal dysfunction in Parkinson's disease with dementia: a 6-[18F]fluoro-L-dopa PET study. Brain. (2002) 125:135865. doi: 10.1093/brain/awf134

112. Nagano-Saito A, Kato T, Arahata Y, Washimi Y, Nakamura A, Abe $\mathrm{Y}$, et al. Cognitive- and motor-related regions in Parkinson's disease: FDOPA and FDG PET studies. NeuroImage. (2004) 22:553-61. doi: 10.1016/j.neuroimage.2004.01.030

113. van Beilen M, Portman AT, Kiers HAL, Maguire RP, Kaasinen V, Koning $\mathrm{M}$, et al. Striatal FDOPA uptake and cognition in advanced non-demented Parkinson's disease: a clinical and FDOPA-PET study. Parkinsonism Relat Disord. (2008) 14:224-8. doi: 10.1016/j.parkreldis.2007.08.011

114. Nobili F, Campus C, Arnaldi D, De Carli F, Cabassi G, Brugnolo A, et al. Cognitive-nigrostriatal relationships in de novo, drug-naïve Parkinson's disease patients: a [I-123]FP-CIT SPECT Study. Move Disord. (2010) 25:3543. doi: $10.1002 / \mathrm{mds} .22899$

115. Polito C, Berti V, Ramat S, Vanzi E, De Cristofaro MT, Pellican,ò G, et al. Interaction of caudate dopamine depletion and brain metabolic changes with cognitive dysfunction in early Parkinson's disease. Neurobiol Aging. (2012) 33:206.e29-39. doi: 10.1016/j.neurobiolaging.2010.09.004

116. Niethammer M, Tang CC, Ma Y, Mattis PJ, Ko JH, Dhawan V, et al. Parkinson's disease cognitive network correlates with caudate dopamine. NeuroImage. (2013) 78:204-9. doi: 10.1016/j.neuroimage.2013.03.070

117. Sawamoto N, Piccini P, Hotton G, Pavese N, Thielemans K, Brooks DJ. Cognitive deficits and striato-frontal dopamine release in Parkinson's disease. Brain. (2008) 131:1294-302. doi: 10.1093/brain/awn054

118. Christopher L, Duff-Canning S, Koshimori Y, Segura B, Boileau I, Chen $\mathrm{R}$, et al. Salience network and parahippocampal dopamine dysfunction in memory-impaired parkinson disease. Ann Neurol. (2015) 77:26980. doi: $10.1002 /$ ana. 24323

119. Bohnen NI, Kaufer DI, Ivanco LS, Lopresti B, Koeppe RA, Davis JG, et al. Cortical cholinergic function is more severely affected in Parkinsonian dementia than in Alzheimer disease. Arch Neurol. (2003) 60:17458. doi: 10.1001/archneur.60.12.1745

120. Hilker R, Thomas AV, Klein JC, Weisenbach S, Kalbe E, Burghaus L, et al. Dementia in Parkinson disease: functional imaging of cholinergic and dopaminergic pathways. Neurology. (2005) 65:1716-22. doi: 10.1212/01.wnl.0000191154.78131.f6

121. Gilman S, Koeppe RA, Nan B, Wang CN, Wang X, Junck L, et al. Cerebral cortical and subcortical cholinergic deficits in parkinsonian syndromes. Neurology. (2010) 74:1416-23. doi: 10.1212/WNL.0b013e3181dc1a55

122. Klein JC, Eggers C, Kalbe E, Weisenbach S, Hohmann C, Vollmar $S$, et al. Neurotransmitter changes in dementia with Lewy bodies and Parkinson disease dementia in vivo. Neurology. (2010) 74:88592. doi: 10.1212/WNL.0b013e3181d55f61

123. Kotagal V, Müller MLTM, Kaufer DI, Koeppe RA, Bohnen NI. Thalamic cholinergic innervation is spared in Alzheimer disease compared to parkinsonian disorders. Neurosci Lett. (2012) 514:169-72. doi: 10.1016/j.neulet.2012.02.083

124. Shimada H, Hirano S, Sinotoh H, Ota T, Tanaka N, Sato K, et al. Dementia with lewy bodies can be well-differentiated from Alzheimer's disease by measurement of brain acetylcholinesterase activity - a [11C]MP4A PET study. Int J Geriatr Psychiatry. (2015) 30:1105-13. doi: 10.1002/gps.4338

125. Meyer PM, Strecker K, Kendziorra K, Becker G, Hesse S, Woelpl D, et al. Reduced $\alpha 4 \beta 2^{*}$-nicotinic acetylcholine receptor binding and its relationship to mild cognitive and depressive symptoms in Parkinson disease. Arch Gen Psychiatry. (2009) 66:866-77. doi: 10.1001/archgenpsychiatry.2009.106

126. Colloby S, Pery E, Pakrasi S, Pimlott S, Wyper D, McKeith I, et al. Nicotinic 123I-5IA-85380 single photon emission computed tomography as a predictor of cognitive progression in Alzheimer's disease and dementia with Lewy bodies. Am J Geriatr Psychiatry. (2010) 18:86-90. doi: 10.1097/JGP.0b013e3181b972aa

127. Edison P, Rowe CC, Rinne JO, Ng S, Ahmed I, Kemppainen N, et al. Amyloid load in Parkinson's disease dementia and Lewy body dementia measured with [11C]PIB positron emission tomography. $J$ Neurol Neurosurg Psychiatry. (2008) 79:1331-8. doi: 10.1136/jnnp.2007. 127878

128. Jokinen P, Scheinin N, Aalto S, Någren K, Savisto N, Parkkola R, et al. [11C]PIB-, [18F]FDG-PET and MRI imaging in patients with Parkinson's disease with and without dementia. Parkinsonism Relat Disord. (2010) 16:666-70. doi: 10.1016/j.parkreldis.2010.08.021

129. Gomperts SN, Locascio JJ, Rentz D, Santarlasci A, Marquie M, Johnson KA, et al. Amyloid is linked to cognitive decline in patients with Parkinson disease without dementia. Neurology. (2013) 80:85-91. doi: 10.1212/WNL.0b013e31827b1a07

130. Petrou M, Dwamena BA, Foerster BR, Maceachern MP, Bohnen NI, Müller ML, et al. Amyloid deposition in Parkinson's disease and cognitive impairment: a systematic review. Move Disord. (2015) 30:92835. doi: $10.1002 / \mathrm{mds} .26191$

131. Shah N, Frey KA, Müller MLTM, Petrou M, Kotagal V, Koeppe RA, et al. Striatal and cortical $\beta$-Amyloidopathy and cognition in Parkinson's disease. Move Disord. (2016) 31:111-7. doi: 10.1002/mds.26369

132. Ahktar R, Xie S, Chen Y, Rick J, Gross R, Nasrallah I, et al. Regional brain amyloid- $\beta$ Accumulation associates with domain-specific cognitive performance in Parkinson disease without dementia. PLoS ONE. (2017) 12:e0177924. doi: 10.1371/journal.pone.0177924 
133. Fiorenzato E, Biundo R, Cecchin D, Frigo AC, Kim J, Weis L, et al. Brain amyloid contribution to cognitive dysfunction in early-stage Parkinson's disease: the PPMI dataset. J Alzheimers Dis. (2018) 66:22937. doi: 10.3233/JAD-180390

134. Melzer TR, Stark MR, Keenan RJ, Myall DJ, MacAskill MR, Pitcher TL, et al. Beta amyloid deposition is not associated with cognitive impairment in Parkinson's disease. Front Neurol. (2019) 10:391. doi: 10.3389/fneur.2019.00391

135. Na S, Jeong H, Park JS, Chung YA, Song IU. The impact of amyloidbeta positivity with $18 \mathrm{f}$-florbetaben pet on neuropsychological aspects in parkinson's disease dementia. Metabolites. (2020) 10:380. doi: 10.3390/metabo 10100380

136. Biundo R, Weis L, Fiorenzato E, Pistonesi F, Cagnin A, Bertoldo $A$, et al. The contribution of beta-amyloid to dementia in Lewy body diseases: a 1-year follow-up study. Brain Commun. (2021) 3:fcab180. doi: 10.1093/braincomms/fcab180

137. Gomperts SN, Locascio JJ, Makaretz SJ, Schultz A, Caso C, Vasdev N, et al. Tau positron emission tomographic imaging in the lewy body diseases. JAMA Neurol. (2016) 73:1334-41. doi: 10.1001/jamaneurol.2016.3338

138. Kantarci K, Lowe VJ, Boeve BF, Senjem ML, Tosakulwong N, Lesnick TG, et al. AV-1451 tau and $\beta$-amyloid positron emission tomography imaging in dementia with Lewy bodies. Ann Neurol. (2017) 81:5867. doi: 10.1002/ana. 24825

139. Buongiorno M, Antonelli F, Compta Y, Fernandez Y, Pavia J, Lomeña F, et al. Cross-sectional and longitudinal cognitive correlates of FDDNP PET and CSF amyloid- $\beta$ and tau in Parkinson's disease. J Alzheimers Dis. (2017) 55:1261-72. doi: 10.3233/JAD-160698

140. Edison P, Ahmed I, Fan Z, Hinz R, Gelosa G, Ray Chaudhuri K, et al. Microglia, amyloid, and glucose metabolism in parkinson's disease with and without dementia. Neuropsychopharmacology. (2013) 38:93849. doi: 10.1038/npp.2012.255

141. Fan Z, Aman Y, Ahmed I, Chetelat G, Landeau B, Ray Chaudhuri K, et al. Influence of microglial activation on neuronal function in Alzheimer's and Parkinson's disease dementia. Alzheimers Dement. (2015) 11:60821.e7. doi: 10.1016/j.jalz.2014.06.016

142. Femminella GD, Ninan S, Atkinson R, Fan Z, Brooks DJ, Edison P. Does microglial activation influence hippocampal volume and neuronal function in Alzheimer's disease and Parkinson's disease dementia? J Alzheimers Dis. (2016) 51:1275-89. doi: 10.3233/JAD-150827

143. Wilson H, Dervenoulas G, Pagano G, Tyacke RJ, Polychronis S, Myers J, et al. Imidazoline 2 binding sites reflecting astroglia pathology in Parkinson's disease: an in vivo 11C-BU99008 PET study. Brain. (2019) 142:311628. doi: 10.1093/brain/awz260

144. Meyer PT, Frings L, Hellwig S. Update on SPECT and PET in parkinsonism - part 2: biomarker imaging of cognitive impairment in Lewy-body diseases. Curr Opin Neurol. (2014) 27:398-404. doi: 10.1097/WCO.0000000000000107

145. Gasca-Salas C, Clavero P, García-García D, Obeso JA, Rodríguez-Oroz MC. Significance of visual hallucinations and cerebral hypometabolism in the risk of dementia in Parkinson's disease patients with mild cognitive impairment. Hum Brain Mapp. (2016) 37:968-77. doi: 10.1002/hbm.23080

146. Tang CC, Poston KL, Dhawan V, Eidelberg D. Abnormalities in metabolic network activity precede the onset of motor symptoms in Parkinson's disease. J Neurosci. (2010) 30:1049-56. doi: 10.1523/JNEUROSCI.4188-09.2010

147. Meles SK, Renken RJ, Pagani M, Teune LK, Arnaldi D, Morbelli S, et al. Abnormal pattern of brain glucose metabolism in Parkinson's disease: replication in three European cohorts. Eur J Nucl Med Mol Imaging. (2020) 47:437-50. doi: 10.1007/s00259-019-04570-7

148. Schrag A, Siddiqui UF, Anastasiou Z, Weintraub D, Schott JM. Clinical variables and biomarkers in prediction of cognitive impairment in patients with newly diagnosed Parkinson's disease: a cohort study. Lancet Neurol. (2017) 16:66-75. doi: 10.1016/S1474-4422(16)30328-3

149. Sampedro F, Marín-Lahoz J, Martínez-Horta S, Pagonabarraga J, Kulisevsky J. Dopaminergic degeneration induces early posterior cortical thinning in Parkinson's disease. Neurobiol Dis. (2019) 124:29-35. doi: 10.1016/j.nbd.2018.11.001

150. Müller MLTM, Bohnen NI. Cholinergic dysfunction in parkinson's disease. Curr Neurol Neurosci Rep. (2013) 13:377. doi: 10.1007/s11910-013-0377-9
151. Bohnen NI, Kanel P, Müller MLTM. Molecular imaging of the cholinergic system in Parkinson's disease. Int Rev Neurobiol. (2018) 141:21150. doi: 10.1016/bs.irn.2018.07.027

152. Bohnen NI, Albin RL, Müller MLTM, Petrou M, Kotagal V, Koeppe NI, et al. Frequency of cholinergic and caudate nucleus dopaminergic deficits across the predemented cognitive spectrum of parkinson disease and evidence of interaction effects. JAMA Neurol. (2015) 72:194200. doi: 10.1001/jamaneurol.2014.2757

153. Pimlott SL, Piggott M, Owens J, Greally E, Court JA, Jaros E, et al. Nicotinic acetylcholine receptor distribution in Alzheimer's disease, dementia with lewy bodies, Parkinson's disease, and vascular dementia: in vitro binding study using 5-[125I]-A-85380. Neuropsychopharmacology. (2004) 29:10816. doi: 10.1038/sj.npp.1300302

154. Kehagia AA, Barker RA, Robbins TW. Cognitive impairment in Parkinson's disease: the dual syndrome hypothesis. Neurodegenerat Dis. (2012) 11:7992. doi: $10.1159 / 000341998$

155. Winer JR, Maass A, Pressman P, Stiver J, Schonhaut DR, Baker SL, et al. Associations between Tau, $\beta$-amyloid, and cognition in Parkinson disease. JAMA Neurol. (2018) 75:227-35. doi: 10.1001/jamaneurol.2017.3713

156. Wang Q, Liu Y, Zhou J. Neuroinflammation in Parkinson's disease and its potential as therapeutic target. Transl Neurodegenerat. (2015) 4:19. doi: 10.1186/s40035-015-0042-0

157. Le W, Wu J, Tang Y. Protective microglia and their regulation in Parkinson's disease. Front Mol Neurosci. (2016) 9:89. doi: 10.3389/fnmol.2016.00089

158. McGeer PL, McGeer EG. Inflammation and neurodegeneration in Parkinson's disease. Parkinsonism Relat Disord. (2004) 10(Suppl 1):S37. doi: 10.1016/j.parkreldis.2004.01.005

159. Kouli A, Camacho M, Allinson K, Williams-Gray CH. Neuroinflammation and protein pathology in Parkinson's disease dementia. Acta Neuropathol Commun. (2020) 8:211. doi: 10.1186/s40478-020-01083-5

160. Best L, Ghadery C, Pavese N, Tai YF, Strafella AP. New and Old TSPO PET radioligands for imaging brain microglial activation in neurodegenerative disease. Curr Neurol Neurosci Rep. (2019) 19:24. doi: 10.1007/s11910-019-0934-y

161. Terada T, Yokokura M, Yoshikawa E, Futatsubashi M, Kono S, Konishi T, et al. Extrastriatal spreading of microglial activation in Parkinson's disease: a positron emission tomography study. Annal Nucl Med. (2016) 30:57987. doi: 10.1007/s12149-016-1099-2

162. Volterra A, Meldolesi J. Astrocytes, from brain glue to communication elements: the revolution continues. Nat Rev Neurosci. (2005) 6:62640. doi: $10.1038 / \mathrm{nrn} 1722$

163. Olmos G, Alemany R, Escriba PV, García-Sevilla JA. The effects of chronic imidazoline drug treatment on glial fibrillary acidic protein concentrations in rat brain. $\mathrm{Br} J$ Pharmacol. (1994) 111:997-1002. doi: 10.1111/j.1476-5381.1994.tb14842.x

164. Booth HDE, Hirst WD, Wade-Martins R. The role of astrocyte dysfunction in Parkinson's disease pathogenesis. Trends Neurosci. (2017) 40:35870. doi: 10.1016/j.tins.2017.04.001

165. Hammes J, Theis H, Giehl K, Hoenig MC, Greuel A, Tittgemeyer M, et al. Dopamine metabolism of the nucleus accumbens and frontostriatal connectivity modulate impulse control. Brain. (2019) 142:73343. doi: 10.1093/brain/awz007

166. Pellicano C, Niccolini F, Wu K, O’Sullivan SS, Lawrence AD, Lees AJ, et al. Morphometric changes in the reward system of Parkinson's disease patients with impulse control disorders. J Neurol. (2015) 262:265361. doi: 10.1007/s00415-015-7892-3

167. Tessitore A, Santangelo G, De Micco R, Vitale C, Giordano A, Raimo $\mathrm{S}$, et al. Cortical thickness changes in patients with Parkinson's disease and impulse control disorders. Parkinsonism Relat Disord. (2016) 24:11925. doi: $10.1016 /$ j.parkreldis.2015.10.013

168. Biundo R, Weis L, Facchini S, Formento-Dojot P, Vallelunga A, Pilleri M, et al. Patterns of cortical thickness associated with impulse control disorders in Parkinson's disease. Move Disord. (2015) 30:688-95. doi: 10.1002/mds. 26154

169. Imperiale F, Agosta F, Canu E, Markovic V, Inuggi A, JecmenicaLukic $\mathrm{M}$, et al. Brain structural and functional signatures of impulsivecompulsive behaviours in Parkinson's disease. Mol Psychiatry. (2018) 23:45966. doi: $10.1038 / \mathrm{mp} .2017 .18$ 
170. Tessitore A, De Micco R, Giordano A, di Nardo F, Caiazzo G, Siciliano $\mathrm{M}$, et al. Intrinsic brain connectivity predicts impulse control disorders in patients with Parkinson's disease. Move Disord. (2017) 32:17109. doi: 10.1002/mds.27139

171. Ye Z, Hammer A, Münte TF. Pramipexole modulates interregional connectivity within the sensorimotor network. Brain Connect. (2017) 7:25863. doi: 10.1089/brain.2017.0484

172. Ricciardi L, Lambert C, De Micco R, Morgante F, Edwards M. Can we predict development of impulsive-compulsive behaviours in Parkinson's disease? J Neurol Neurosurg Psychiatry. (2018) 89:47681. doi: 10.1136/jnnp-2017-317007

173. Yoo HB, Lee JY, Lee JS, Kang H, Kim YK, Song IC, et al. Whole-brain diffusion-tensor changes in parkinsonian patients with impulse control disorders. J Clin Neurol. (2015) 11:42-7. doi: 10.3988/jen.2015.11.1.42

174. Canu E, Agosta F, Markovic V, Petrovic I, Stankovic I, Imperiale $\mathrm{F}$, et al. White matter tract alterations in Parkinson's disease patients with punding. Parkinsonism Relat Disord. (2017) 43:85-91. doi: 10.1016/j.parkreldis.2017.07.025

175. Zadeh MM, Ashraf-Ganjouei A, Sherbaf FG, Haghshomar M, Aarabi MH. White matter tract alterations in drug-Naïve Parkinson's disease patients with impulse control disorders. Front Neurol. (2018) 9:163. doi: 10.3389/fneur.2018.00163

176. Carriere N, Lopes R, Defebvre L, Delmaire C, Dujardin K. Impaired corticostriatal connectivity in impulse control disorders in Parkinson disease. Neurology. (2015) 84:2116-23. doi: 10.1212/WNL.0000000000001619

177. Tessitore A, Santangelo G, De Micco R, Giordano A, Raimo S, Amboni M, et al. Resting-state brain networks in patients with Parkinson's disease and impulse control disorders. Cortex. (2017) 94:63-72. doi: 10.1016/j.cortex.2017.06.008

178. Petersen K, Van Wouwe N, Stark A, Lin YC, Kang H, Trujillo-Diaz P, et al. Ventral striatal network connectivity reflects reward learning and behavior in patients with Parkinson's disease. Hum Brain Mapp. (2018) 39:509-21. doi: 10.1002/hbm.23860

179. Navalpotro-Gomez I, Kim J, Paz-Alonso PM, Delgado-Alvarado M, Quiroga-Varela A, Jimenez-Urbieta $H$, et al. Disrupted salience network dynamics in Parkinson's disease patients with impulse control disorders. Parkinsonism Relat Disord. (2020) 70:74-81. doi: 10.1016/j.parkreldis.2019.12.009

180. Koh J, Kaneoke Y, Donishi T, Ishida T, Sakata M, Hiwatani $\mathrm{Y}$, et al. Increased large-scale inter-network connectivity in relation to impulsivity in Parkinson's disease. Sci Rep. (2020) 10:11418. doi: 10.1038/s41598-020-68266-X

181. Mata-Marín D, Pineda-Pardo JÁ, Molina JA, Alonso-Frech F, Vela L, Obeso I. Aberrant salient and corticolimbic connectivity in hypersexual Parkinson's disease. Brain Connect. (2021). doi: 10.1089/brain.2020.0868. [Epub ahead of print].

182. Rao H, Mamikonyan E, Detre JA, Siderowf AD, Stern MB, Potenza MN, et al. Decreased ventral striatal activity with impulse control disorders in Parkinson's Disease. Move Disord. (2010) 25:1660-9. doi: 10.1002/mds. 23147

183. Frosini D, Pesaresi I, Cosottini M, Belmonte G, Rossi C, Dell'Osso L, et al. Parkinson's disease and pathological gambling: results from a functional MRI study. Move Disord. (2010) 25:2449-53. doi: 10.1002/mds.23369

184. Voon V, Gao J, Brezing C, Symmonds M, Ekanayake V, Fernandez H, et al. Dopamine agonists and risk: Impulse control disorders in Parkinson's; Disease. Brain. (2011) 134:1438-46. doi: 10.1093/brain/awr080

185. Politis M, Loane C, Wu K, O'Sullivan SS, Woodhead Z, Kiferle L, et al. Neural response to visual sexual cues in dopamine treatment-linked hypersexuality in Parkinson's disease. Brain. (2013) 136:400-11. doi: 10.1093/brain/aws326

186. Girard R, Obeso I, Thobois S, Park SA, Vidal T, Favre E, et al. Wait and you shall see: sexual delay discounting in hypersexual Parkinson's disease. Brain. (2019) 142:146-62. doi: 10.1093/brain/awy298

187. Paz-Alonso PM, Navalpotro-Gomez I, Boddy P, Dacosta-Aguayo R, Delgado-Alvarado M, Quiroga-Varela A, et al. Functional inhibitory control dynamics in impulse control disorders in Parkinson's disease. Move Disord. (2020) 35:316-25. doi: 10.1002/mds.27885

188. Haagensen BN, Herz DM, Meder D, Madsen KH, Løkkegaard A, Siebner HR. Linking brain activity during sequential gambling to impulse control in Parkinson's disease. NeuroImage Clin. (2020) 27:102330. doi: 10.1016/j.nicl.2020.102330

189. Tahmasian M, Rochhausen L, Maier F, Williamson KL, Drzezga A, Timmermann L, et al. Impulsivity is associated with increased metabolism in the fronto-insular network in Parkinson's Disease. Front Behav Neurosci. (2015) 9:317. doi: 10.3389/fnbeh.2015.00317

190. Verger A, Klesse E, Chawki MB, Witjas T, Azulay JP, Eusebio A, et al. Brain PET substrate of impulse control disorders in Parkinson's disease: a metabolic connectivity study. Hum Brain Mapp. (2018) 39:317886. doi: 10.1002/hbm. 24068

191. Marín-Lahoz J, Sampedro F, Horta-Barba A, Martínez-Horta S, AracilBolaños I, Camacho V, et al. Preservation of brain metabolism in recently diagnosed Parkinson's impulse control disorders. Eur J Nucl Med $\mathrm{Mol}$ Imaging. (2020) 47:2165-74. doi: 10.1007/s00259-019-04664-2

192. Cilia R, Ko JH, Cho SS, van Eimeren T, Marotta G, Pellecchia G, et al. Reduced dopamine transporter density in the ventral striatum of patients with Parkinson's disease and pathological gambling. Neurobiol Dis. (2010) 39:98-104. doi: 10.1016/j.nbd.2010.03.013

193. Joutsa J, Martikainen K, Niemelä S, Johansson J, Forsback S, Rinne $\mathrm{JO}$, et al. Increased medial orbitofrontal [18F]fluorodopa uptake in Parkinsonian impulse control disorders. Move Disord. (2012) 27:77882. doi: 10.1002/mds. 24941

194. Voon V, Rizos A, Chakravartty R, Hulholland N, Robinson S, Howell N, et al. Impulse control disorders in Parkinson's disease: decreased striatal dopamine transporter levels. J Neurol Neurosurg Psychiatry. (2014) 85:148-52.

195. Vriend C, Nordbeck AH, Booij J, van der Werf YD, Pattij T, Voorn $\mathrm{P}$, et al. Reduced dopamine transporter binding predates impulse control disorders in Parkinson's disease. Move Disord. (2014) 29:90411. doi: $10.1002 / \mathrm{mds} .25886$

196. Smith KM, Xie SX, Weintraub D. Incident impulse control disorder symptoms and dopamine transporter imaging in Parkinson disease. J Neurol Neurosurg Psychiatry. (2016) 87:864-70. doi: 10.1136/jnnp-2015-311827

197. Premi E, Pilotto A, Garibotto V, Bigni B, Turrone R, Alberici A, et al. Impulse control disorder in PD: a lateralized monoaminergic frontostriatal disconnection syndrome? Parkinsonism Relat Disord. (2016) 30:62-6. doi: 10.1016/j.parkreldis.2016.05.028

198. Navalpotro-Gomez I, Dacosta-Aguayo R, Molinet-Dronda F, Martin-Bastida A, Botas-Peñin A, Jimenez-Urbieta $\mathrm{H}$, et al. Nigrostriatal dopamine transporter availability, and its metabolic and clinical correlates in Parkinson's disease patients with impulse control disorders. Eur J Nucl Med Mol Imaging. (2019) 46:2065-76. doi: 10.1007/s00259-019-04396-3. [Epub ahead of print].

199. Hinkle JT, Mills KA, Perepezko K, Pontone GM. Bidirectional correlations between dopaminergic function and motivation in Parkinson's disease. J Geriatr Psychiatry Neurol. (2021) 891988721996802. doi: 10.1177/0891988721996802

200. Boileau I, Guttman M, Rusjan P, Adams J, Houle S, Tong J, et al. Decreased binding of the D3 dopamine receptor-preferring ligand [11C](+)-PHNO in drug-naive Parkinson's disease. Brain. (2009) 132(Pt 5):136675. doi: 10.1093/brain/awn337

201. Payer D, Guttman M, Kish S, Tong J, Strafella A, Zack M, et al. [ $\left.{ }^{11} \mathrm{C}\right]-$ $(+)$-PHNO PET imaging of dopamine $\mathrm{D}(2 / 3)$ receptors in Parkinson's disease with impulse control disorders. Mov Disord. (2015) 30:160-6. doi: $10.1002 / \mathrm{mds} .26135$

202. Stark AJ, Smith CT, Petersen KJ, Trujillo P, Van Wouwe NC, Donahue MJ, et al. $\left[{ }^{18} \mathrm{~F}\right]$ fallypride characterization of striatal and extrastriatal $\mathrm{D}_{2 / 3}$ receptors in Parkinson's disease. Neuroimage Clin. (2018) 18:433-42. doi: 10.1016/j.nicl.2018.02.010

203. Van Eimeren T, Pellecchia G, Cilia R, Ballanger B, Steeves TDL, Houle S, et al. Drug-induced deactivation of inhibitory networks predicts pathological gambling in PD. Neurology. (2010) 75:1711-6. doi: 10.1212/WNL.0b013e3181fc27fa

204. Antonelli F, Ko J, Miyaski J, Lang A, Houle S, Valzania F, et al. Dopamine-agonists and impulsivity in Parkinson's disease: Impulsive choices vs. impulsive actions. Hum Brain Mapp. (2014) 35:2499-506. doi: 10.1002/hbm.22344

205. Steeves TDL, Miyasaki J, Zurowski M, Lang AE, Pellecchia G, Van Eimeren $\mathrm{T}$, et al. Increased striatal dopamine release in Parkinsonian patients 
with pathological gambling: a [11C] raclopride PET study. Brain. (2009) 132:1376-85. doi: 10.1093/brain/awp054

206. O'Sullivan SS, Wu K, Politis M, Lawrence AD, Evans AH, Bose SK, et al. Cue-induced striatal dopamine release in Parkinson's disease-associated impulsive-compulsive behaviours. Brain. (2011) 134:969-78. doi: 10.1093/brain/awr003

207. Ray N, Miyaski J, Zurowski M, Ko J, Choo S, Pellecchia G, Antonelli F, et al. Extrastriatal dopaminergic abnormalities of DA homeostasis in Parkinson's patients with medication-induced pathological gambling: A [11C] FLB-457 and PET study. Neurobiol Dis. (2012) 48:519-25. doi: 10.1016/j.nbd.2012.06.021

208. Wu K, Politis M, O’Sullivan SS, Lawrence AD, Warsi S, Bose S, et al. Single versus multiple impulse control disorders in Parkinson's disease: an 11C-raclopride positron emission tomography study of reward cue-evoked striatal dopamine release. J Neurol. (2015) 262:150414. doi: 10.1007/s00415-015-7722-7

209. Cilia R, Siri C, Marotta G, Isaias IU, De Gaspari D, Canesi M, et al. Functional abnormalities underlying pathological gambling in parkinson disease. Arch Neurol. (2008) 65:1604-11. doi: 10.1001/archneur.65.12.1604

210. Martini A, Tamburin S, Biundo R, Weis L, Antonini A, Pizzolo C, et al. Incentive-driven decision-making networks in de novo and drug-treated Parkinson's disease patients with impulsive-compulsive behaviors: a systematic review of neuroimaging studies. Parkinsonism Relat Disord. (2020) 78:165-77. doi: 10.1016/j.parkreldis.2020. 07.020

211. Seibyl JP, Marchek KL, Quinlan D, Sheff K, Zoghbi S, Zea-Ponce $\mathrm{Y}$, et al. Decreased single-photon emission computed tomographic $\{123 I\} \beta$-CIT striatal uptake correlates with symptom severity in parkinson's disease. Annal Neurol. (1995) 38:589-98. doi: 10.1002/ana.410 380407

212. Lee JY, Seo SH, Kim YK, Yoo HB, Kim YE, Song IC, et al. Extrastriatal dopaminergic changes in Parkinson's disease patients with impulse control disorders. J Neurol Neurosurg Psychiatry. (2014) 85:2330. doi: 10.1136/jnnp-2013-305549

213. Voon V, Napier TC, Frank MJ, Sgambato-Faure V, Grace AA, RodriguezOroz $\mathrm{M}$, et al. Impulse control disorders and levodopa-induced dyskinesias in Parkinson's disease: an update. Lancet Neurol. (2017) 16:238-50. doi: 10.1016/S1474-4422(17)30004-2

214. Honkanen EA, Saari L, Orte K, Gardberg M, Noponen T, Joutsa J, et al. No link between striatal dopaminergic axons and dopamine transporter imaging in Parkinson's disease. Move Disord. (2019) 34:15626. doi: $10.1002 / \mathrm{mds} .27777$

215. Majuri J, Joutsa J. Molecular imaging of impulse control disorders in Parkinson's disease. Eur J Nucl Med Mol Imaging. (2019) 46:222022. doi: 10.1007/s00259-019-04459-5

216. Brittain JS, Watkins KE, Joundi RA, Ray NJ, Holland P, Green AL, et al. A role for the subthalamic nucleus in response inhibition during conflict. J Neurosci. (2012) 32:13396-401. doi: 10.1523/JNEUROSCI.2259-12.2012

Conflict of Interest: AM-B, MD-A, and IN-G declare that the research was conducted in the absence of any commercial or financial relationships that could be construed as a potential conflict of interest. MR-O received financial support for her research from national and local government institutions in Spain (Carlos III Institute of Health, Navarra Government) and honoraria from Insightec, and Boston Scientific for lectures, travel and accommodation to attend scientific meetings.

Publisher's Note: All claims expressed in this article are solely those of the authors and do not necessarily represent those of their affiliated organizations, or those of the publisher, the editors and the reviewers. Any product that may be evaluated in this article, or claim that may be made by its manufacturer, is not guaranteed or endorsed by the publisher.

Copyright (c) 2021 Martín-Bastida, Delgado-Alvarado, Navalpotro-Gómez and Rodríguez-Oroz. This is an open-access article distributed under the terms of the Creative Commons Attribution License (CC BY). The use, distribution or reproduction in other forums is permitted, provided the original author(s) and the copyright owner(s) are credited and that the original publication in this journal is cited, in accordance with accepted academic practice. No use, distribution or reproduction is permitted which does not comply with these terms. 